\title{
Occupant action patterns regarding spatial and human factors in office environments
}

\author{
Laura Marín-Restrepo a, ${ }^{\mathrm{*}}$, Maureen Trebilcock b, Mark Gillott c \\ a Faculty of Architecture, Construction and Design, Universidad del Bío-Bío, Concepción, Chile \\ ${ }^{\mathrm{b}}$ Department of Architectural Design and Theory, Faculty of Architecture, Construction and Design, Universidad del Bí-Bío, Concepción, Chile \\ ${ }^{\mathrm{c}}$ Department of Architecture and Built Environment, Faculty of Engineering, University of Nottingham, UK
}

\begin{abstract}
Since occupant behaviour impacts the energy performance of buildings, its study is relevant in order to bridge the performance gap. While the factors influencing occupant behaviour have been established, most studies have focused on those factors that motivate the action, such as environmental and temporal conditions. Contextual factors including spatial and occupant characteristics, which act as action moderators, remain a subject to explore. In this way, this article aims to identify patterns in the occupants' actions in office environments, based on spatial and human factors. A field study, including 514 occupants in 85 office spaces, was carried out in 11 buildings in Concepción, Chile. The results indicate that spatial layout is significantly related to the operation of windows, blinds, and thermostats, but not personal devices. Gender did not influence whether an occupant was active or not and age range was only significant regarding blinds. In shared spaces, there were fewer active occupants and whose acts depend on the perception of opportunity that they have, which is associated with element control distance and occupant age. The findings suggest that the probability that actions occur varies based on spatial and human factors, particularly because these factors affect occupant perception of opportunity.
\end{abstract}

Keywords: occupant behaviour, office spaces, spatial layout, adaptive actions, active occupant, perceived opportunity, occupant position

\section{Introduction}

In recent years, numerous studies have been conducted on occupant behaviour and its influence on the thermal and energy performance of buildings [1-3], given that it has been found that occupants play a key role in the gap between expected and real performance during building operation [4-6]. Thus, human behaviour has been studied with a special emphasis on the occupant actions that demand energy, in order to understand it $[7,8]$, evaluate its impact $[9,10]$ and integrate it into simulations for more accurate predictions [11,12].

According to the adaptive thermal comfort model, occupants carry out actions to remain comfortable [13]. Hence, they are active subjects that can modify their environment or adjust to it [14], either requiring energy or not, which implies a high potential for energy savings [15,16]. The actions taken by an occupant can be categorized as physiological, personal, spatial and environmental [17]. This last category involves interaction with control elements in the space that have the potential to modify the indoor environmental conditions, such as windows, solar shading devices or HVAC systems. Therefore, they are of particular interest to architectural design. A complete list of actions by category is described by Schweiker, Carlucci, Andersen, Dong and O'Brien [17].

\footnotetext{
* Corresponding author at: Faculty of Architecture, Construction and Design, Universidad del Bío-Bío, Avda. Collao 1202, 4081112, Concepción-Chile; E-mail address: Imadim@gmail.com
} 
Various approaches have been proposed to study these actions, including fieldwork, laboratory experiments [18] and lately, virtual reality [19]. The former allows exploring the phenomena in its usual environment and identifying the influencing factors, while experiments allow quantifying the impact of those factors since they are studied in a controlled environment; although both approaches have been used to develop mathematical models. Registering actions is a complex task. It can be made directly, through monitoring with equipment and sensors, which allows recording the exact moment when an action occurs, but it is constrained by availability and costs which can reduce the total number of participants [20] and at the same time, sensors cannot explain all the complexities associated with human behaviour [18]. Actions can also be recorded indirectly, through surveys or interviews, which might be subject to bias since they rely on the participant $[18,21]$. However, they have been used in large studies to understand occupant behaviour and identify trends [22,23], as well as to develop models [24,25].

Several influencing factors have been identified to be able to anticipate occupant behaviour. In the DNAS framework, "drivers" are defined as the factors that influence the execution of actions and are classified into five types, those associated with: the building, the occupant, the environment, the systems, and the time [26]. More recent investigations suggest that actions are motivated by adaptive and non-adaptive triggers and are moderated by contextual factors [17] that can be grouped as physical, physiological, psychological, and social, as proposed initially by Fabi, Andersen, Corgnati and Olesen [27].

Most studies have focused on environmental and time-related factors, which are clearly quantifiable [28] by addressing the problem from the point of view of "the action" and showing the physical and temporal conditions in which it is most likely that an action occurs [29], developing models through different modelling techniques such as logistic regressions, Markov processes, agent-based or decision trees [21,30]. However, few studies have investigated contextual factors, which are scarcely reported [31] or overlooked [32]. They are usually considered just as characteristics which delimit the study, instead of being influencing factors as such. Although they have been identified and are understood to be action moderators, is not yet clear how these factors are associated with the performance of actions. The contextual factors are many and varied, ranging from personality traits [33] to building characteristics [34] and availability of control elements [35].

The location and accessibility of control elements has frequently been cited as influencing occupant interaction with them [31,36,37], as well as interior design and the presence of multiple occupants [38]. Nonetheless, little information is understood about these factors. It has been demonstrated that desk location, spatial layout, and orientation highly contribute to user environmental satisfaction [39-41] and comfort in workplaces [42-44]. In the same way, it has been stated that the occupant's perception of the indoor environment depends on their position in the space [45]. Yet, distance to the control element and the occupant orientation regarding it, are potential influencing factors that have not been quantified in relation to the action. The most studied factor related with buildings may be facade orientation, probably 
because it is directly related with some environmental factors such as solar radiation. It has been demonstrated that windows and blinds in facades with higher solar radiation are used more frequently that those with less solar exposure [23,46,47]. However, these studies have examined the state of the blinds, rather than the associated occupant who operates it.

Moreover, it has been reported that actions frequency decreases in shared spaces, although most of these studies have been conducted in laboratories [48] or with few people in the shared space [49]. As yet, the phenomena have not been addressed in real open plan offices. It is essential to take into consideration that because of the challenges that studying groups of people entail, most studies focus on individual occupants or on a few occupants that have the direct possibility to operate control elements [50,51]. Consequently, shared office spaces, i.e. with multiple occupants, are still a field to be explored.

It has also been stated that gender and age are associated with the performance of the actions [23]. This is most likely because they have an impact on energy consumption [52,53] and saving attitudes [54], as well as thermal comfort perception [55-57]. Nevertheless, there are few studies on their relationships with the actions themselves, like [58,59].

Furthermore, previous research has reported the importance of perceived control on thermal comfort and energy use in buildings [60-62], as well as on IEQ satisfaction [63]. Nonetheless, few studies have addressed this in relation with the performance of actions like [36,48], probably because most studies are conducted in spaces where the opportunity to operate control elements is clear. Yun, Steemers and Baker [25] argue that "occupants with high perceived control tended to use their windows more frequently than others with a low level of perceived control". However, to date there is no consensus about how the position and characteristics of the occupants influence perceived opportunity when they have to share the space.

Together, these studies establish that contextual factors and the way they are related to the occupants' actions and perception of opportunity are relevant to deeper study, in a real-world context, with multiple occupants. For this reason, this research intends to study some of the factors that enable or restrict the performance of actions, rather than determining what motivates them, an area that has been widely covered in the literature. Contextual factors are grouped here into two categories: spatial factors, those that have a direct link with the physical spaces, and therefore can be designed; and human factors, those that are part of people, their social, psychological and physiological dynamics.

In this way, this paper aims to identify patterns in the occupants that perform environmental adaptive actions in office spaces, based on spatial and human factors, in order to get insights about how these factors are related with occupants' actions. First, if there is a relationship between the indicated factors and an occupant operating a control element such as a window is determined. Then, whether there are common characteristics between those who take action and those who do not is analysed, identifying patterns. 
Likewise, the relationship of these factors with the perception of opportunity is studied, as well as if patterns exist, since this could be associated with the performance of actions.

108

\section{Methodology}

Due to the nature of the phenomenon, the methodology was based on fieldwork and an analysis of the relationships between variables that occur naturally. A longitudinal survey in office environments was performed with the objective of recording the occupants' actions as well as their perception of their opportunity to operate the studied control elements, following similar studies like $[23,64,65]$. However, rather than aiming to identify the environmental and temporal factors influencing the action, the survey attempted to collect different environmental and temporal conditions where an action could occur, to later contrast against the contextual factors, since these factors were constants. To gather information about spatial and human factors, the occupants' characteristics were registered through a short questionnaire and the indoor design conditions were recorded during the fieldwork.

The environmental actions considered for this study and their related control elements are window opening/closing; solar shading device adjustment, such as blinds; use of personal control devices for heating or cooling, such as fans or heaters; and the use of thermostats. The relationship between occupants' actions and the following contextual factors is studied: 1) Spatial factors: spatial layout (open plan offices, shared enclosed offices and individual offices), occupant orientation relative to control elements (front, back, left or right), element orientation in relation to north (8 orientations), and distance from the occupant to the element. The latter three were studied only for the windows and blinds; 2) Human factors: gender and age. Figure 1 illustrates the spatial and human factors studied as well as the actions and their control elements considered in this research. 


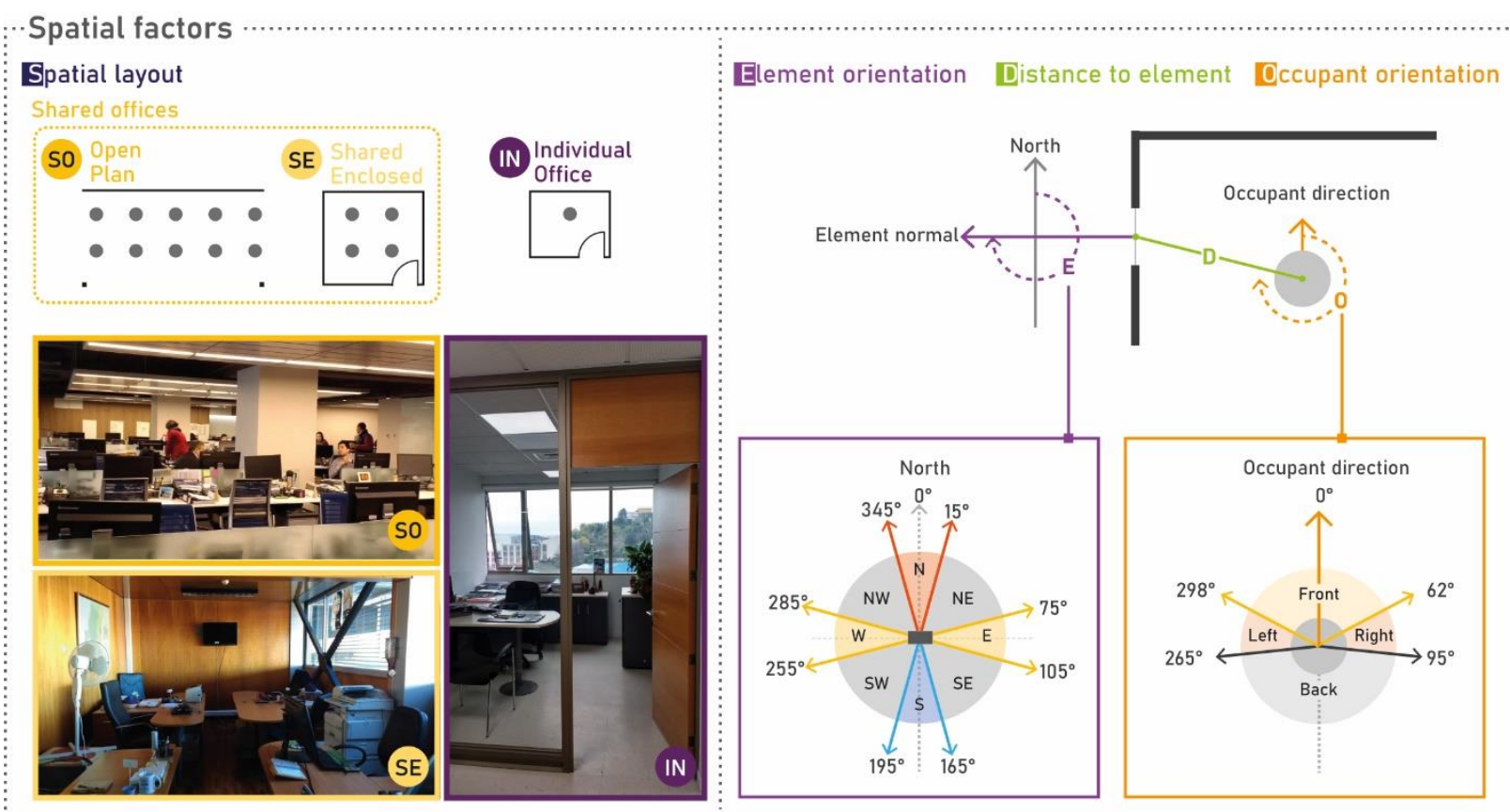

\section{..Human factors}

Gender

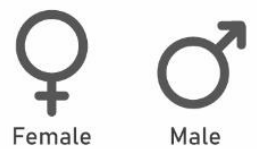

Age Range

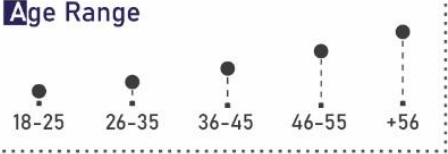

Actions and control elements

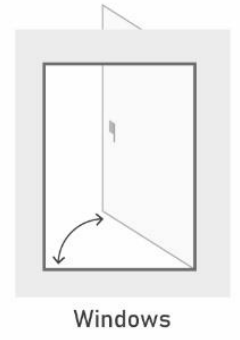

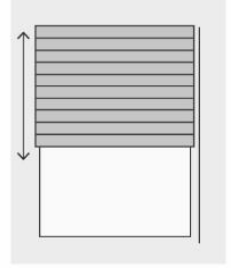

Blinds

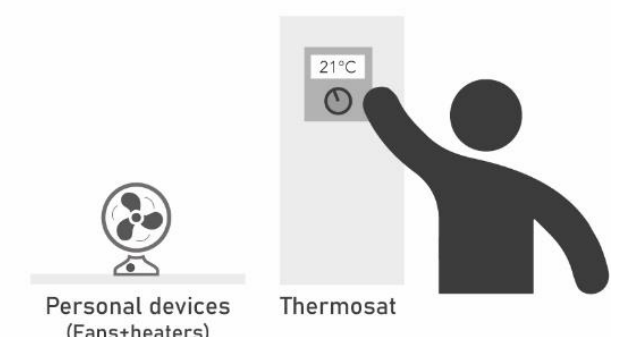

Figure 1. Spatial and human factors studied including their categories. Spatial factors are Spatial layout: Open space (SO), Shared Enclosed space (SE), Individual space (IN); Occupant orientation relative to control elements (front, back, left or right); element orientation ( 8 orientations) and distance from the occupant to the element. Human factors are gender and age range. The actions and their control elements considered in this research are also presented.

\subsection{Data collection}

Fieldwork was carried out between July 2017 and February 2018 in 11 office buildings located in the city of Concepción, Chile $\left(36^{\circ} \mathrm{S}\right.$ latitude, $73^{\circ} \mathrm{W}$ longitude). This city has a Mediterranean-oceanic climate (Köppen Csb), with no extreme winters or summers. The average temperatures in January (summer) range from $10.9{ }^{\circ} \mathrm{C}$ to $22.8^{\circ} \mathrm{C}$ and in July (winter) vary from $5.8^{\circ} \mathrm{C}$ to $13.2^{\circ} \mathrm{C}$ [66]. For this reason, buildings commonly offer passive adaptive opportunities (operable windows and blinds), as well as active opportunities (personal control devices and thermostats), thereby making it possible to study the actions of interest. 

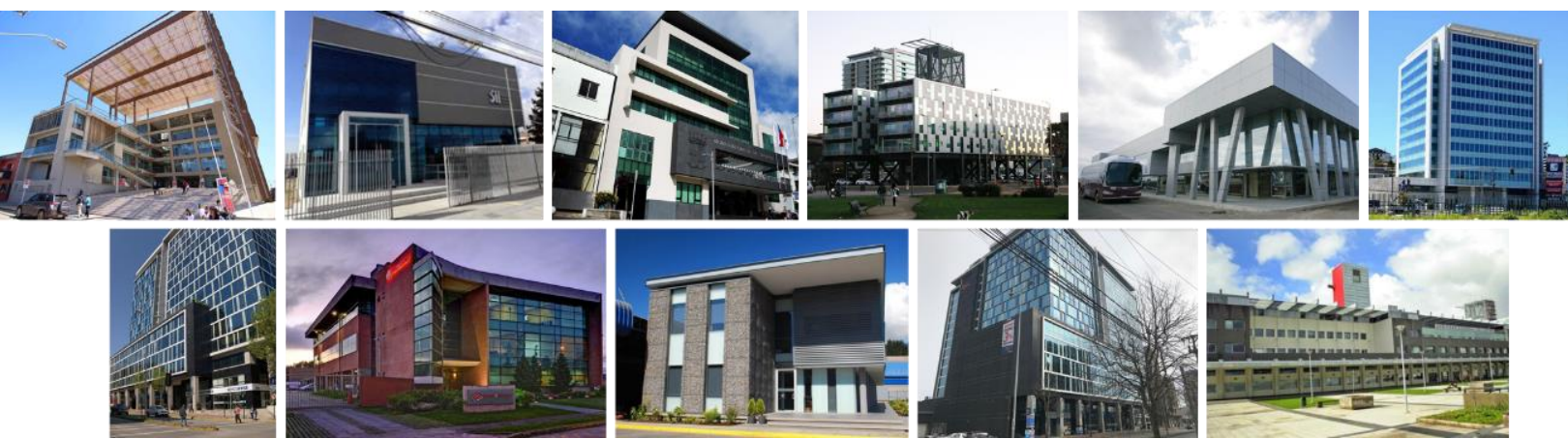

Figure 2. Office buildings studied

The office buildings examined (Figure 2) were purposely selected according to the variety of adaptation opportunities they have and possible access for the research team. Table 1 summarizes the cases and their main characteristics, in addition to the total studied areas (85). These zones were not selected previously and were chosen by the manager in each building according to institutional availability. In each building, the studied areas were classified according to their spatial layout, as presented in Figure 1: Open plan spaces (SO), with more than 8 people; shared enclosed spaces (SE), which included between 2 and 8 people; and Individual spaces (IN). Although the first two are both shared offices, they are differentiated due to the level of control and adaptation opportunities that a smaller scale space can provide. Detailed information regarding the physical characteristics of studied zones and their occupants can be found in the supplementary material.

Table 1. Study cases and their characteristics, showing the total studied areas by spatial layout

\begin{tabular}{|c|c|c|c|c|c|c|c|c|c|c|c|}
\hline \multirow[b]{2}{*}{ Case } & \multirow{2}{*}{$\begin{array}{l}\text { Year } \\
\text { built }\end{array}$} & \multirow[b]{2}{*}{ Levels } & \multirow{2}{*}{$\begin{array}{c}\text { Floors } \\
\text { studied }\end{array}$} & \multirow{2}{*}{$\begin{array}{l}\text { Operable } \\
\text { windows }\end{array}$} & \multirow{2}{*}{$\begin{array}{c}\text { Operable } \\
\text { blinds }\end{array}$} & \multirow{2}{*}{$\begin{array}{c}\text { Personal control } \\
\text { devices } \mathrm{h} / \mathrm{c}\end{array}$} & \multirow{2}{*}{$\begin{array}{l}\text { HVAC } \\
\text { system }\end{array}$} & \multicolumn{3}{|c|}{ Total studied areas } & \multirow{2}{*}{$\begin{array}{c}\text { Total } \\
\text { occupants }\end{array}$} \\
\hline & & & & & & & & SO & SE & IN & \\
\hline A & 2016 & 6 & 1 and 2 & Yes & Some areas & Yes & Some areas & 4 & 1 & 10 & 71 \\
\hline B & 2016 & 2 & GF and 1 & Yes & Some areas & Yes & Yes & 2 & 1 & 2 & 31 \\
\hline C & 2016 & 8 & 3 and 6 & Yes & Yes & Some areas & Yes & 2 & 5 & 14 & 60 \\
\hline $\mathrm{D}$ & 2005 & 6 & 2 and 5 & Yes & Yes & Yes & Yes & 4 & 2 & 6 & 45 \\
\hline $\mathrm{E}$ & 2016 & 2 & GF and 1 & Yes & Yes & Yes & Yes & 1 & 4 & 3 & 32 \\
\hline $\mathrm{F}$ & 2013 & 13 & 1 and 8 & Some areas & Yes & Yes & Yes & 3 & 1 & 2 & 131 \\
\hline G & 2015 & 16 & 5 & Yes & Yes & Yes & Yes & 3 & 1 & - & 40 \\
\hline $\mathrm{H}$ & 2009 & 3 & GF & Yes & Yes & Yes & No & 2 & 2 & - & 55 \\
\hline I & 2013 & 2 & GF and 1 & Some areas & Yes & Yes & Yes & 2 & 4 & 2 & 39 \\
\hline$X$ & 2007 & 4 & 3 & Yes & Yes & Yes & No & - & 1 & - & 7 \\
\hline \multirow[t]{2}{*}{$\mathrm{Y}$} & 2015 & 7 & 6 & Yes & Yes & Yes & No & - & 1 & - & 3 \\
\hline & & & & & & & Total & 23 & 23 & 39 & 514 \\
\hline
\end{tabular}

SO: Open plan spaces, SE: Shared Enclosed spaces, IN: Individual spaces, GF: ground floor

Considering that some studies have found that occupant behaviour varies according to the season and time of day, but that the trend is similar within the same season and time $[64,67,68]$, in each building the surveys were conducted face-to-face three times a day (morning, midday and late afternoon) for one day in winter, one day in spring, and one day in summer. Thus, the occupants had the opportunity to respond to the questionnaire up to 9 times, although the number of times the occupants participated varied due to normal office dynamics and their availability. In certain cases, some of the occupants surveyed were replaced between seasons, so that in spring and summer new occupants participated in positions that had previously been surveyed. For this reason, the same spatial position may have more than one participant. 
The questionnaire was designed as "right-now", seeking to capture answers associated with the actions in the instant in which the instrument was completed. However, for this study, data were grouped to perform a wider analysis focused on the occupants' profile rather than time or seasonal effects. This is further explained in the data analysis section.

The question used on the survey to gather the information about the opportunities and adaptive actions is presented in Figure 3. This question was designed to identify: 1) if an occupant perceived he or she had the opportunity to use a certain control element, and 2) if an occupant used the respective element during the surveyed period, that is to say, if the action occurred. An answer was required for each of the control elements associated with the actions of interest for this study (windows, blinds, fans o heaters -personal control devices-, thermostats).

Since you arrived at the office or since the last time you answered the survey, have you made any adjustments to the following environmental controls?

$\begin{array}{c:cccc}\begin{array}{c}\text { Does not apply / } \\ \text { Do not have control }\end{array} & \begin{array}{c}\text { You have not made any } \\ \text { adjustments }\end{array} & \begin{array}{c}\text { You opened } \\ \text { (turned on/increased) } \\ \text { without asking others }\end{array} & \begin{array}{c}\text { You opened } \\ \text { (turned on/increased) } \\ \text { after asking others }\end{array} & \begin{array}{c}\text { You closed } \\ \text { (turned off/decreased) } \\ \text { without asking others } \\ \text { (turned off/decreased) } \\ \text { after asking others }\end{array} \\ \text { No opportunity } & \begin{array}{c}\text { Action } \\ \text { Perceived Opportunity }\end{array}\end{array}$

Figure 3. Question about the occupant actions related to the control elements (windows, blinds, fans o heaters -personal control devices-, thermostats) and possible responses. The classification according to the response is also included. Please be aware that the survey was carried out in Spanish.

In addition, an occupant characterization section was included in the first questionnaire that the occupant answered, where gender and age range, as well as the spatial layout of his or her work zone were recorded. This information was later contrasted with the planimetry of each building.

For each space studied, planimetric information was gathered, including the location of windows and blinds. The position of the occupants who took part was detailed on the space's floor plan along with the direction in which they look when seated working. Similarly, the presence of personal control devices such as fans and heaters were recorded, in addition to control elements such as centralised HVAC systems and thermostats, although the exact location of these elements was not registered since the focus was on the architectural design elements. These data were later included in a BIM model of each case.

\subsection{Data processing}

With the information collected, the spatial opportunities available in each office space were identified, where a "spatial opportunity" is understood to be the presence of the control element in the space, as observed by the researchers. In this way, each zone was classified according to whether one or more control elements existed there: operable windows, blinds, heaters, fans and/or thermostats. Afterwards, since each occupant belonged to a specific office space, it was established whether the occupant had the spatial opportunity to operate each element.

Based on the responses to the indicated question, each questionnaire was classified according to whether the occupant perceived he or she had the opportunity to operate each control element and if he or she 
operated them, as shown in Figure 3. Regarding the opportunity, each control element was classified as:

194 a) The occupant did not perceive that he or she has the opportunity, if the response was "does not apply/do not have control"; or b) The occupant perceived he or she has the opportunity, if the response was one of the other options, given that they imply the recognition of the existence of the element. Moreover, each control element was categorized according to whether the occupant operated it, either as : a) The action did not occur, if the response was "does not apply/do not have control" or "Has not made any adjustment"; or b) The action occurred, if the response was one of the other options.

Since the occupant is taken as the unit of analysis, the questionnaires from the same participant were grouped and processed to classify each occupant for each element/action. In this way, it was considered that an occupant perceived the opportunity to operate the control element when he or she identified the opportunity in at least one of the questionnaires. In the same sense, it was considered that an occupant performed an action if he or she recorded that an action occurred in at least one of their answered questionnaires. This simplification seeks to explore the data as well as recognize the occupants who performed an action and perceived opportunity. It assumes that on a daily basis those who carry out the actions tend to be the same and that the perception of opportunity does not vary over time. Through this process, the two outcome variables associated with each occupant were defined: action and perceived opportunity.

Regarding the spatial factors, the occupants' distance to and their orientation with the closest window and blinds, as well as the orientation of these elements in relation to north were extracted from the BIM models by means of a Dynamo script in Autodesk Revit. The script associates each occupant with the closest window/blinds in their zone and returns data on their distance in a horizontal plane, the occupant's orientation in relation to the element (front, left, behind and right), and the element orientation (North, Northeast, East, South, Southeast, West, Northwest), as illustrated in Figure 1. The human factors (gender and age range) were extracted from the questionnaire linked to each occupant.

In this way, gender and age range, spatial layout, occupant distance to and orientation regarding the closest window and blinds, as well as the orientation of these elements in relation to the north were associated as attributes of each occupant, defining their corresponding spatial and human factors, the predictors variables for this research.

\subsection{Data analysis}

As this study seeks to identify the factors related to the performance of an action, for the analysis of each element, only those occupants with the corresponding spatial opportunity were considered, so this attribute was used as a filter for subsequent analyses.

Since this research seeks patterns in the occupants' actions regarding spatial and human factors, the 
the perceived opportunity to operate the control elements could be related to both the action and the factors studied, so this characteristic is also considered for data analysis. These characteristics are considered here as the outcome variables, which are expected to be related to the factors studied. Thus, the spatial and human factors (See Figure 1) are the predictor variables for this research.

First, it was studied if there is a relationship between whether an occupant performed an action or not and the spatial and human factors (A). Secondly, since perceived control has been shown to be related to the use of control elements, the same previous relationship was studied, but it only considers those occupants who perceived having the opportunity (APO). Finally, the perceived opportunity (PO) rather than the action was addressed, in order to study whether an occupant perceived opportunity or not in relation to spatial and human factors. The brackets show the coding for the analysis sets, which are summarised in Figure 4 .

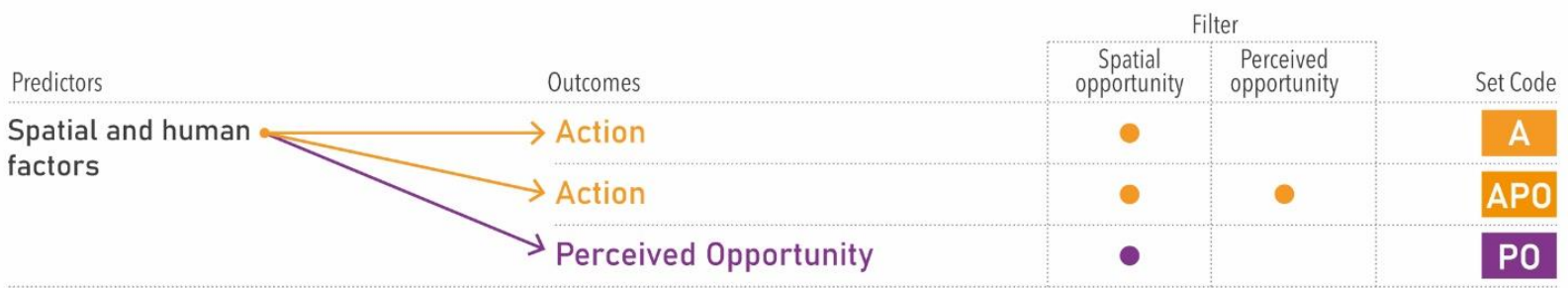

Figure 4. Analysis sets. A (Action) studies if there is a relationship between whether an occupant performed an action or not and the spatial and human factors. APO (Action + Perceived Opportunity) considers the effect of perceived opportunity on the action, studying if there is a relationship between whether an occupant performed an action or not and the spatial and human factors, but considering only those occupants who perceived having the opportunity to use the control elements. PO (Perceived Opportunity) studies whether an occupant perceived opportunity or not in relation to spatial and human factors. All the sets consider only the occupants with spatial opportunity.

The analysis was divided into two parts: the first determined the relationship between the spatial and human factors and occupants' actions and perceived opportunity, according to the defined analysis sets; while the second explored the patterns in those relationships that were found to be significant.

The statistical analysis was carried out using the software SPSS (version 24). Since the outcome variables for this study are categorical, and the predictors are both categorical and continuous (just the distance), the bivariate analysis is differentiated according to the type of data (categorical-categorical and continuous-categorical). In concordance with other studies of this kind, the significance level was defined as $p<0.05$ [69].

In order to compare the differences between categorical groups and following previous studies in the field $[55,63]$, the Chi-squared test for independence was applied to test whether there is a relationship between variables. This is demonstrated if there are changes in the proportions of the occupants who performed an action or perceived opportunity according to the spatial and human factors. Cramer's V was used for effect size quantification. This indicator gives a number between 0 and 1, showing the strength of the relationship between the two categorical variables, where 0.1 is small, 0.3 medium and 0.5 large [70]. Values less than 0.1 are then considered negligible and over that value, the relationships are of interest. Since both the Chi- 
square test or Cramer's V do not identify the patterns of the relationship [63,71], to that aim, standardized histograms were plotted and standardized residuals were calculated $[69,71]$.

In the case of distance, the only continuous variable studied, Spearman's correlation coefficient (@) was used to determine the strength of the relationship between variables. This coefficient was chosen because of the type of data and because it does not rely on the assumptions of the linear model [72]. It was interpreted based on Ferguson [73], like similar studies [43,74], where absolute values of $\varrho<0.20=$ negligible; $0.20 \leq \mathrm{Q}<0.50=$ small; $0.50 \leq \mathrm{Q}<0.80=$ moderate; and $\mathrm{Q} \geq 0.80=$ large. A $t$-test for independent samples was applied to evaluate the difference between groups. To identify patterns in these relationships, logistic regression was used just as previous research has done with continuous variables like illuminance [49] or temperature [65], allowing estimating the likelihood of the outcome variable in function of the predictor variable, in this case, the distance.

\section{Results}

\subsection{The participants and their distribution by studied factors}

A total of 514 occupants participated in the study and 2,327 questionnaires were collected, with an average of $4.53(\mathrm{SD}=2.41)$ per occupant. The number of surveys and participants by spatial layout per case is presented in Table 2. The participants were distributed over 85 office spaces throughout the 11 buildings studied. A similar number of males and females participated in the study and the most common age range was between 36 and 45 years old. Table 3 presents the total occupant distribution by spatial layout, gender and age range, factors studied for all the control elements.

Table 2. Surveys collected and participants by spatial layout per case.

\begin{tabular}{|c|c|c|c|c|c|c|c|c|}
\hline & \multicolumn{2}{|c|}{ SO } & \multicolumn{2}{|c|}{ SE } & \multicolumn{2}{|c|}{ IN } & \multicolumn{2}{|c|}{ Total } \\
\hline Case & Surveys & Participants & Surveys & Participants & Surveys & Participants & Surveys & Participants \\
\hline A & 282 & 58 & 9 & 1 & 45 & 12 & 336 & 71 \\
\hline B & 124 & 27 & 11 & 2 & 13 & 2 & 148 & 31 \\
\hline C & 92 & 16 & 153 & 29 & 57 & 15 & 302 & 60 \\
\hline $\mathrm{D}$ & 159 & 33 & 18 & 5 & 27 & 7 & 204 & 45 \\
\hline E & 8 & 1 & 157 & 28 & 20 & 3 & 185 & 32 \\
\hline F & 435 & 125 & 30 & 4 & 14 & 2 & 479 & 131 \\
\hline G & 148 & 38 & 12 & 2 & - & - & 160 & 40 \\
\hline $\mathrm{H}$ & 232 & 49 & 30 & 6 & - & - & 262 & 55 \\
\hline I & 121 & 22 & 64 & 15 & 11 & 2 & 196 & 39 \\
\hline$X$ & - & - & 37 & 7 & - & - & 37 & 7 \\
\hline Y & - & - & 18 & 3 & - & - & 18 & 3 \\
\hline Total & 1601 & 369 & 539 & 102 & 187 & 43 & 2327 & 514 \\
\hline
\end{tabular}

SO: Shared Open space, SE: Shared Enclosed space, IN: Individual space

Table 3. Occupant distribution by spatial layout, gender and age range

\begin{tabular}{|c|c|c|c|c|c|c|c|c|c|c|c|c|}
\hline & \multicolumn{3}{|c|}{ Spatial Layout } & \multicolumn{3}{|c|}{ Gender } & \multicolumn{6}{|c|}{ Age Range } \\
\hline & $\mathrm{SO}$ & SE & IN & Male & Female & $\begin{array}{c}\text { No } \\
\text { response }\end{array}$ & $18-25$ & $26-35$ & $36-45$ & $46-55$ & +56 & $\begin{array}{c}\text { No } \\
\text { response }\end{array}$ \\
\hline Total participants & 369 & 102 & 43 & 251 & 240 & 23 & 51 & 128 & 163 & 99 & 48 & 25 \\
\hline$\%$ within factor & $71.8 \%$ & $19.8 \%$ & $8.4 \%$ & $48.8 \%$ & $46.7 \%$ & $4.5 \%$ & $9.9 \%$ & $24.9 \%$ & $31.7 \%$ & $19.3 \%$ & $9.3 \%$ & $4.9 \%$ \\
\hline
\end{tabular}


Based on the data extracted from the dynamo script, the occupants' general distribution by their orientation in relation to the closest window and blinds, as well as the orientation of these elements in relation to north, is presented in Table 4. It is worthy of note that not all occupants were in zones with windows or blinds. Likewise, not all windows had associated blinds and that in some cases the blinds were located on glazed facades without operable windows. The general average occupant's distance to the window was $3.63 \mathrm{~m}$ (SD: 3.91, BCa 95\% CI [3.29, 4.00]), and to the blinds was $2.98 \mathrm{~m}$ (SD: 2.40, BCa 95\% CI $[2.77,3.19])$.

Table 4. Distribution of occupant orientation in relation to the element and element orientation

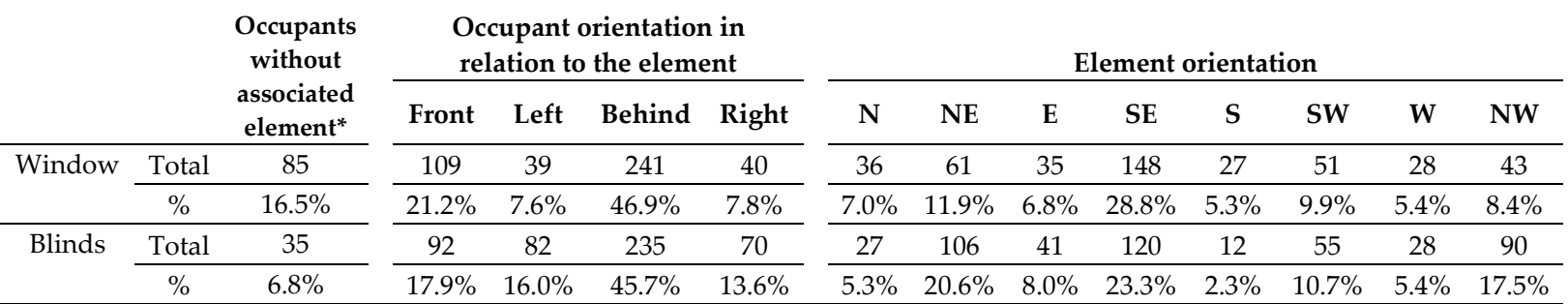

*It refers to those occupants who were in zones without the indicated element, meaning they did not have the spatial opportunity. The remaining occupants which correspond to those with the spatial opportunity of using the indicated elements are differentiated by occupant position regarding the closest element and the element orientation.

\subsection{The occupants' actions and perceived opportunity}

Each of the occupants who took part in this study have different associated spatial opportunities, and for the analysis only those with the corresponding spatial opportunity for each element were considered. Table 5 presents the total number of occupants with the spatial opportunity for each control element based on field observations. Furthermore, Table 5 classifies the occupants according to whether they operated the element or not (Set A), whether they perceived they had an opportunity or not (Set PO), and whether they operated the element or not considering only those who perceived opportunity (Set APO).

Table 5. Occupants with observed spatial opportunity, classified according to the analysis sets.

\begin{tabular}{|c|c|c|c|c|c|c|c|c|c|c|c|c|c|c|}
\hline \multirow[b]{3}{*}{ Element } & \multirow{2}{*}{\multicolumn{2}{|c|}{$\begin{array}{c}\text { Spatial } \\
\text { opportunity }\end{array}$}} & \multicolumn{4}{|c|}{ Action (A) } & \multicolumn{4}{|c|}{$\begin{array}{c}\text { Perceived } \\
\text { Opportunity (PO) }\end{array}$} & \multicolumn{4}{|c|}{$\begin{array}{l}\text { Action + Perceived } \\
\text { Opportunity (APO) }\end{array}$} \\
\hline & & & \multicolumn{2}{|c|}{ Action } & \multicolumn{2}{|c|}{ No action } & \multicolumn{2}{|c|}{ Perceived } & \multicolumn{2}{|c|}{ Did not Perceive } & \multicolumn{2}{|c|}{ Action } & \multicolumn{2}{|c|}{ No action } \\
\hline & Total & $\%$ & Total & $\%$ & Total & $\%$ & Total & $\%$ & Total & $\%$ & Total & $\%$ & Total & $\%$ \\
\hline Window & 429 & $83 \%$ & 121 & $28 \%$ & 308 & $72 \%$ & 340 & $79 \%$ & 89 & $21 \%$ & 121 & $36 \%$ & 219 & $64 \%$ \\
\hline Blinds & 479 & $93 \%$ & 138 & $29 \%$ & 341 & $71 \%$ & 350 & $73 \%$ & 129 & $27 \%$ & 138 & $39 \%$ & 212 & $61 \%$ \\
\hline Personal control devices & 413 & $80 \%$ & 71 & $17 \%$ & 342 & $83 \%$ & 141 & $34 \%$ & 272 & $66 \%$ & 71 & $50 \%$ & 70 & $50 \%$ \\
\hline Thermostat & 361 & $70 \%$ & 48 & $13 \%$ & 313 & $87 \%$ & 247 & $68 \%$ & 114 & $32 \%$ & 48 & $19 \%$ & 199 & $81 \%$ \\
\hline
\end{tabular}

In general, the number of occupants that operated the control elements is less than those who did not, and it is more likely that an occupant does not perform an action. This probability increases when considering only the occupants who perceived opportunity (APO), thereby supporting the idea that it is necessary for an occupant to be aware of the presence of the elements to use them. Likewise, there is evidence that a high proportion of the occupants perceived they do not have an opportunity, when it was in fact observed that the opportunity does exist. It should be noted that around $70 \%$ of the occupants perceived the opportunity to operate the windows, blinds and thermostat, but only a third of them perceived they can use personal control devices such as small heaters or fans. 
The following sections break down the data and analyse whether these proportions change according to spatial and human factors. First, whether there is a relationship between spatial and occupant factors and the occupants' actions and their perception of opportunity is established. Due to the length of this paper, the contingency tables showing the proportions by factor are included as supplementary material and only the statistical test values, p-values and effect size values are presented below. The significant relationships are identified and afterwards, their patterns are presented in the subsequent section.

\subsection{The relationship between spatial and human factors, and occupants' actions and perceived} opportunity.

Table 6 presents the results in relation to spatial factors, indicating which relationships are statistically significant and have at least a small-medium effect size [75]. The results show that the spatial factors related with the occupants' actions are mainly spatial layout, element orientation and distance. The last two are associated with the use of the window and the blinds in all the analysis sets. Spatial layout is related in all sets with the window and thermostat, and with the perception of opportunity in blinds and devices. Occupant orientation was only significant regarding the blinds, particularly in relation to the perceived opportunity.

Table 6. Results of the relationship between spatial factors and the occupants' actions, by analysis sets.

\begin{tabular}{|c|c|c|c|c|c|}
\hline Factor & Element & Set & Statistical test ${ }^{*}$ & p-value ${ }^{* *}$ & Effect size ${ }^{* * *}$ \\
\hline \multirow[t]{12}{*}{ Spatial Layout } & \multirow[t]{3}{*}{ Window } & $\mathrm{A}$ & $\chi^{2}(2, n=429)=21.746$ & $<0.001$ & 0.225 \\
\hline & & $\mathrm{APO}$ & $\chi^{2}(2, n=340)=16.078$ & $<0.001$ & 0.217 \\
\hline & & $\mathrm{PO}$ & $\chi^{2}(2, n=429)=11.827$ & 0.003 & 0.166 \\
\hline & \multirow[t]{3}{*}{ Blinds } & $\mathrm{A}$ & $\chi^{2}(2, n=479)=10.661$ & 0.005 & 0.149 \\
\hline & & $\mathrm{APO}$ & $\chi^{2}(2, n=350)=3.464$ & 0.178 & 0.099 \\
\hline & & $\mathrm{PO}$ & $\chi^{2}(2, n=479)=13.762$ & 0.001 & 0.17 \\
\hline & \multirow{3}{*}{$\begin{array}{l}\text { Personal control } \\
\text { devices } \\
\text { (fans or heaters) }\end{array}$} & $\mathrm{A}$ & $\chi^{2}(2, n=413)=2.147$ & 0.351 & 0.072 \\
\hline & & $\mathrm{APO}$ & $\chi^{2}(2, n=141)=2.192$ & 0.342 & 0.125 \\
\hline & & $\mathrm{PO}$ & $\chi^{2}(2, n=413)=18.782$ & $<0.001$ & 0.213 \\
\hline & \multirow[t]{3}{*}{ Thermostat } & $\mathrm{A}$ & $\chi^{2}(2, n=361)=36.504$ & $<0.001$ & 0.318 \\
\hline & & $\mathrm{APO}$ & $\chi^{2}(2, \mathrm{n}=247)=27.748$ & $<0.001$ & 0.335 \\
\hline & & $\mathrm{PO}$ & $\chi^{2}(2, \mathrm{n}=361)=6.909$ & 0.033 & 0.138 \\
\hline \multirow{6}{*}{$\begin{array}{l}\text { Occupant's } \\
\text { orientation }\end{array}$} & \multirow[t]{3}{*}{ Window } & $\mathrm{A}$ & $\chi^{2}(3, n=429)=2.041$ & 0.567 & 0.069 \\
\hline & & $\mathrm{APO}$ & $\chi^{2}(3, n=340)=2.093$ & 0.552 & 0.078 \\
\hline & & $\mathrm{PO}$ & $\chi^{2}(3, n=429)=0.097$ & 0.992 & 0.015 \\
\hline & \multirow[t]{3}{*}{ Blinds } & $\mathrm{A}$ & $\chi^{2}(3, \mathrm{n}=479)=5.493$ & 0.14 & 0.107 \\
\hline & & $\mathrm{APO}$ & $\chi^{2}(3, n=350)=5.190$ & 0.161 & 0.122 \\
\hline & & $\mathrm{PO}$ & $\chi^{2}(3, n=479)=21.493$ & $<0.001$ & 0.212 \\
\hline \multirow[t]{6}{*}{ Element's orientation } & \multirow[t]{3}{*}{ Window } & $\mathrm{A}$ & $\chi^{2}(7, \mathrm{n}=429)=22.200$ & 0.002 & 0.227 \\
\hline & & $\mathrm{APO}$ & $\chi^{2}(7, \mathrm{n}=340)=15.938$ & 0.026 & 0.217 \\
\hline & & $\mathrm{PO}$ & $\chi^{2}(7, n=429)=25.658$ & 0.001 & 0.245 \\
\hline & \multirow[t]{3}{*}{ Blinds } & $\mathrm{A}$ & $\chi^{2}(7, \mathrm{n}=479)=23.531$ & 0.001 & 0.222 \\
\hline & & $\mathrm{APO}$ & $\chi^{2}(7, n=350)=20.488$ & 0.005 & 0.242 \\
\hline & & $\mathrm{PO}$ & $\chi^{2}(7, \mathrm{n}=479)=23.605$ & 0.001 & 0.222 \\
\hline \multirow[t]{6}{*}{ Distance } & \multirow[t]{3}{*}{ Window } & $\mathrm{A}$ & $\varrho=-0.298[-0.38,-0.22]$ & $<0.001$ & 0.57 \\
\hline & & $\mathrm{APO}$ & $\mathrm{Q}=-0.221[-0.31,-0.12]$ & $<0.001$ & 0.34 \\
\hline & & $\mathrm{PO}$ & $\mathrm{Q}=-0.39[-0.47,-0.30]$ & $<0.001$ & 0.89 \\
\hline & \multirow[t]{3}{*}{ Blinds } & $\mathrm{A}$ & $\varrho=-0.372[-0.45,-0.30]$ & $<0.001$ & 0.78 \\
\hline & & $\mathrm{APO}$ & $\mathrm{Q}=-0.335[-0.43,-0.12]$ & $<0.001$ & 0.54 \\
\hline & & $\mathrm{PO}$ & $\mathrm{Q}=-0.34[-0.42,-0.26]$ & $<0.001$ & 0.86 \\
\hline $\begin{array}{l}\text { A: Action, APO: Action+Per } \\
\text { * Statistical test: Chi-squared } \\
\text { size sample are indicated in } \\
{ }^{* *} \text { p-values in bold are statis } \\
* * * \text { Effect size for Chi-square }\end{array}$ & $\begin{array}{l}\text { ceived Opportunity, } P( \\
\text { d test for all factors exce } \\
\text { brackets. For the latter } \\
\text { tically significant }(p<0 \\
\text { e corresponds to Crame }\end{array}$ & $\begin{array}{l}\text { : Perceive } \\
\text { th for dist }\end{array}$ & $\begin{array}{l}\text { portunity } \\
\text { where Spearman's correlation } \\
\text { e reported in brackets. } \\
\text { nan's correlation it is Cohen's }\end{array}$ & ed. Concer & former, df and \\
\hline
\end{tabular}


Table 7 summarises the results in relation to human factors. It is observed that in general, gender is not associated with an occupant acting or not, or with him or her perceiving having the opportunity or not, except for the operation of the thermostat. In the case of age range, it is associated with the perception of opportunity for all control elements, but not with the use of any.

Table 7. Results of relationship between occupant factors and the performance of actions, by analysis set.

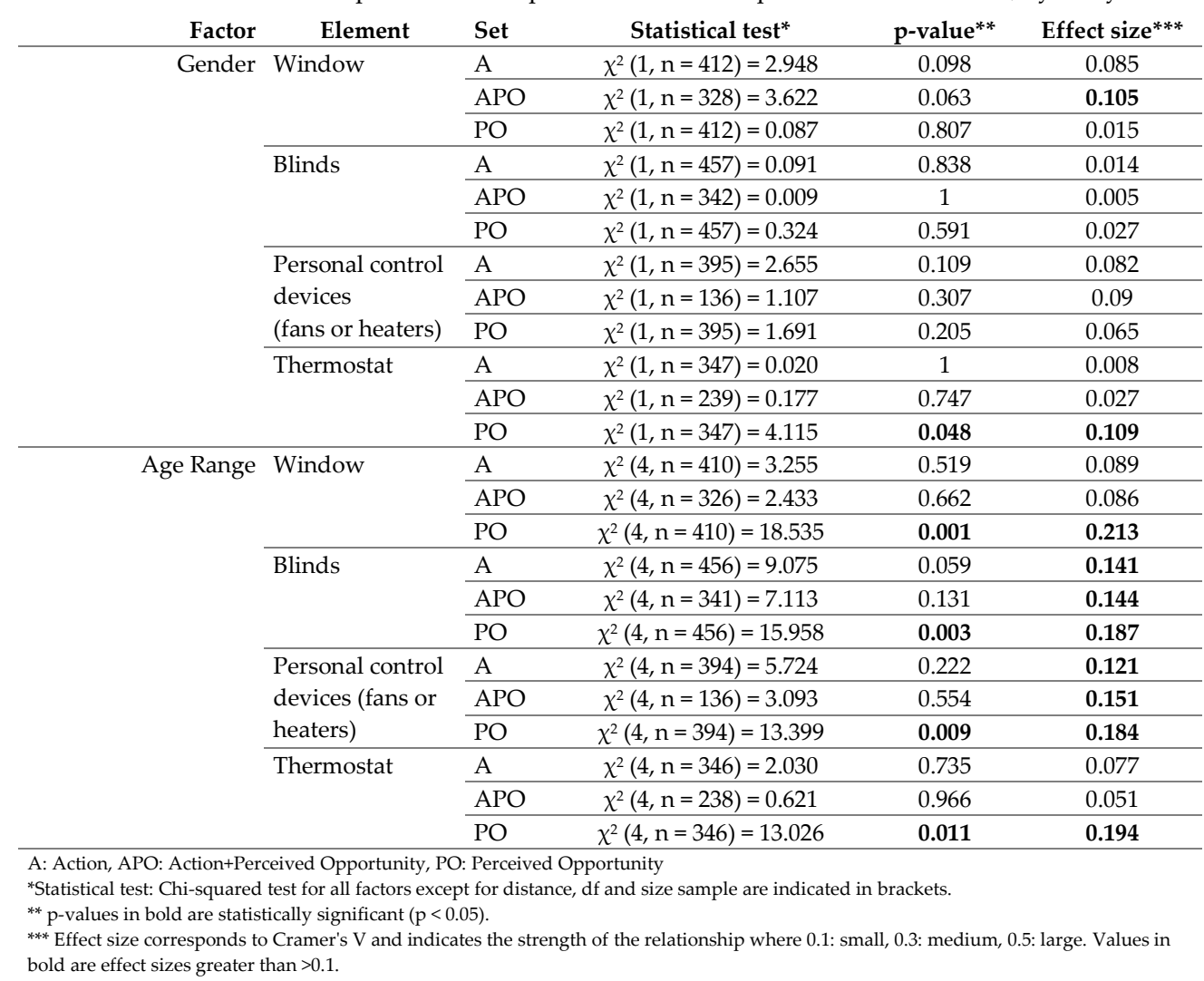

\subsection{Patterns in occupants' actions and perceived opportunity with regard to spatial and human} factors.

The patterns in those factors and analysis sets with a significant relationship are presented below. Relationships with no statistical significance but a small-medium effect size are also included. The graphs marked with a star show statistically significant relationships, while graphs with a circle show nosignificant relationship but small-medium effect size, according to Table 6 and Table 7 . The graphs show the standardised proportions to better visualize whether there are differences in the distribution of the sets. As a guide, the graphs include a dotted line that indicates the general proportion of occupants who acted or not (for the A and APO sets) or who perceived having opportunity or not (PO set), without discriminating by factors. The further a category proportion moves away from this line, the more representative it will be in the relationship between variables. If one category is located below the line, this indicates that fewer of the expected occupants took action or perceived an opportunity, and the opposite is true if it is located above the line. The tables with standardized residuals for all the factors and sets can be found in the supplementary material. 
The proportion of occupants who perform an action according to the spatial layout of their work zone is presented in Figure 5. A clear pattern can be observed regarding the window, blinds and thermostat: there are fewer active occupants in offices with an open plan (SO), their number increases in shared enclosed offices (SE), and there are more in individual offices (IN). The trend is the same for the action sets (A and APO) and could suggest that the more occupants that share an office space, the less they take action.

Regarding PO, the patterns are similar. For all the control elements, in shared offices, in particular those with an open floor plan, a considerable part of the occupants declare they do not have an opportunity,

when they do.

Spatial layout
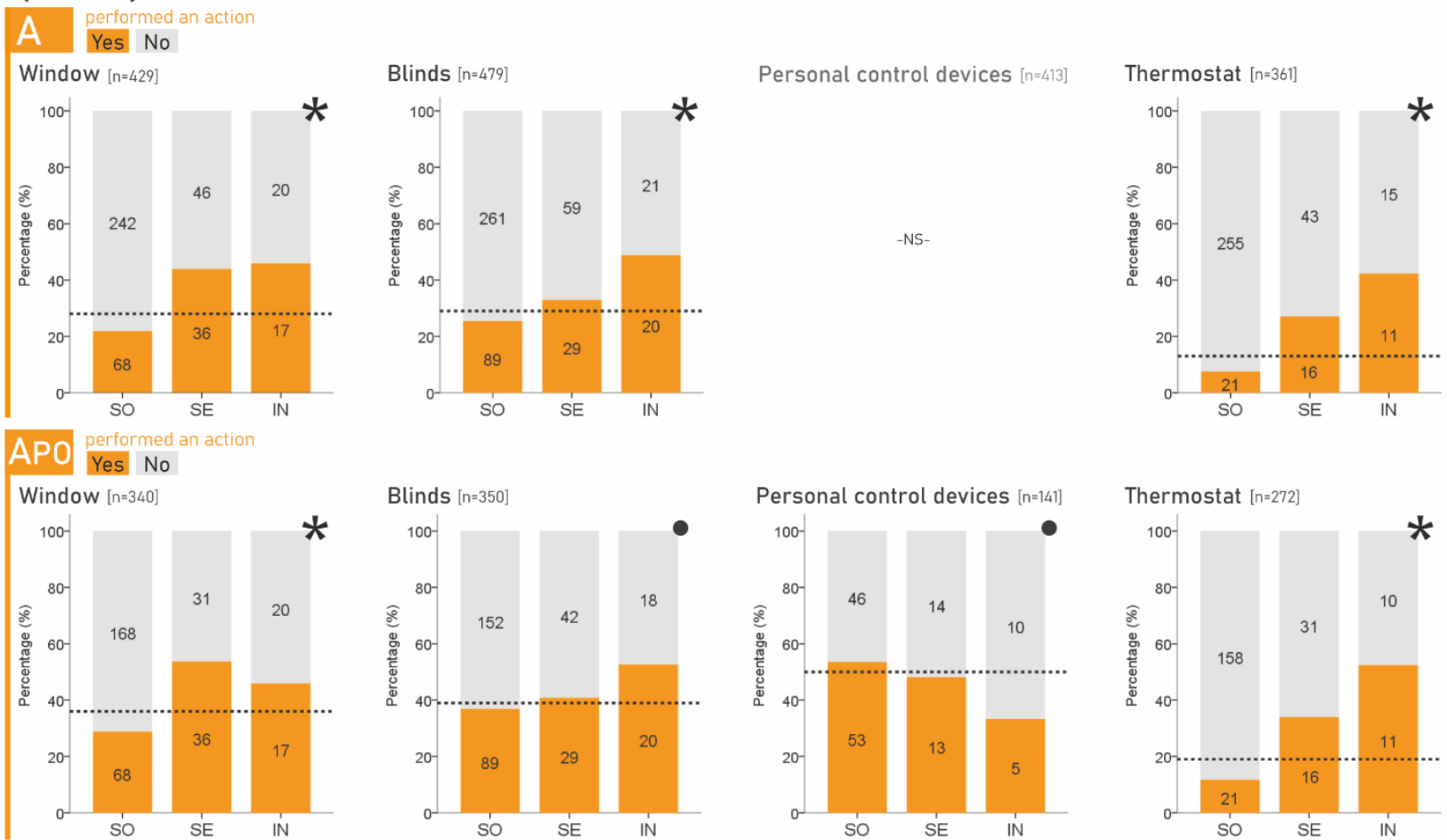

PO perceived
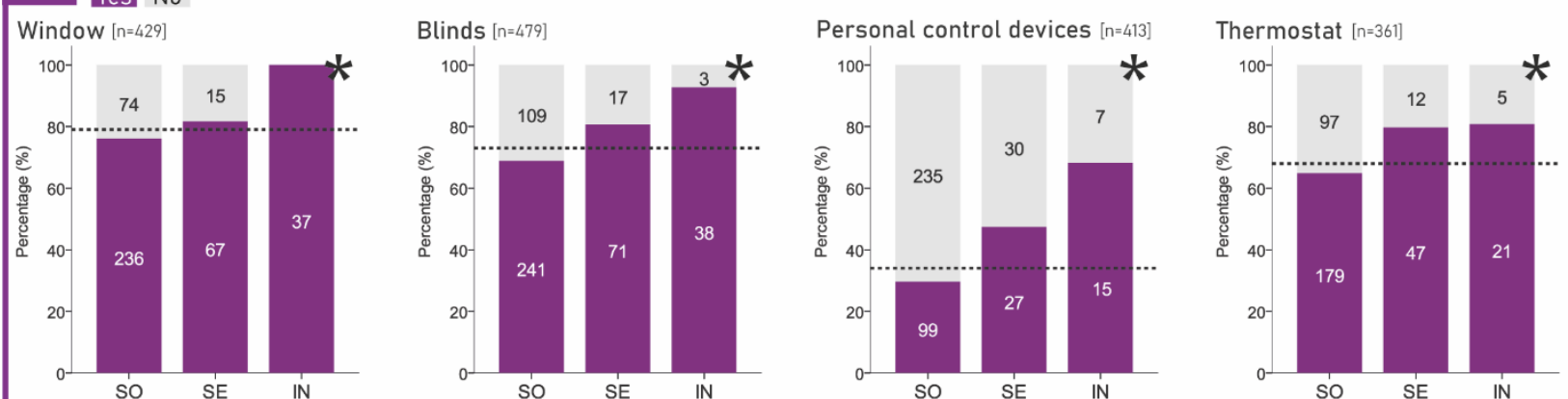

Figure 5. Proportion of occupants that operate the element indicated (A, APO) or that perceived opportunity (PO), by spatial layout. The dashed line indicates the general proportion, presented in Table 5. The number in the bar indicates the total number of occupants. SO: Shared Open space, SE: Shared Enclosed space, IN: Individual space. The graphs marked with a star show statistically significant relationships, while graphs with a circle show no-significant relationship but small-medium effect size.

\subsubsection{Occupants and element orientation}

When the blinds were located behind the occupant, more occupants perceived they have the opportunity to operate them. Likewise, when this element was next to the occupant (left or right), fewer occupants than 
expected perceived they can interact with it (Figure 6 left). Patterns for window and occupant orientation are not included since no relationship was found, thereby suggesting that actions or perceiving opportunity are independent of the way an occupant is oriented regarding the window.

362

The distribution by orientation can be seen in Figure 6 right. The windows facing north had the highest proportion of associated active occupants. In the case of the blinds, those that are located facing west registered the most active occupants. The windows to the southeast were those with the least active associated occupants. The trend is the same for A and APO: more occupants operated the element when it is oriented in such a way that it has more solar exposure. Regarding the PO, the pattern in this association is not clear. In the case of the window, there are more occupants that perceived they do not have an opportunity if the element is oriented towards the southeast, whereas with blinds, there are more occupants with this perception when the element is positioned towards the north and southeast.
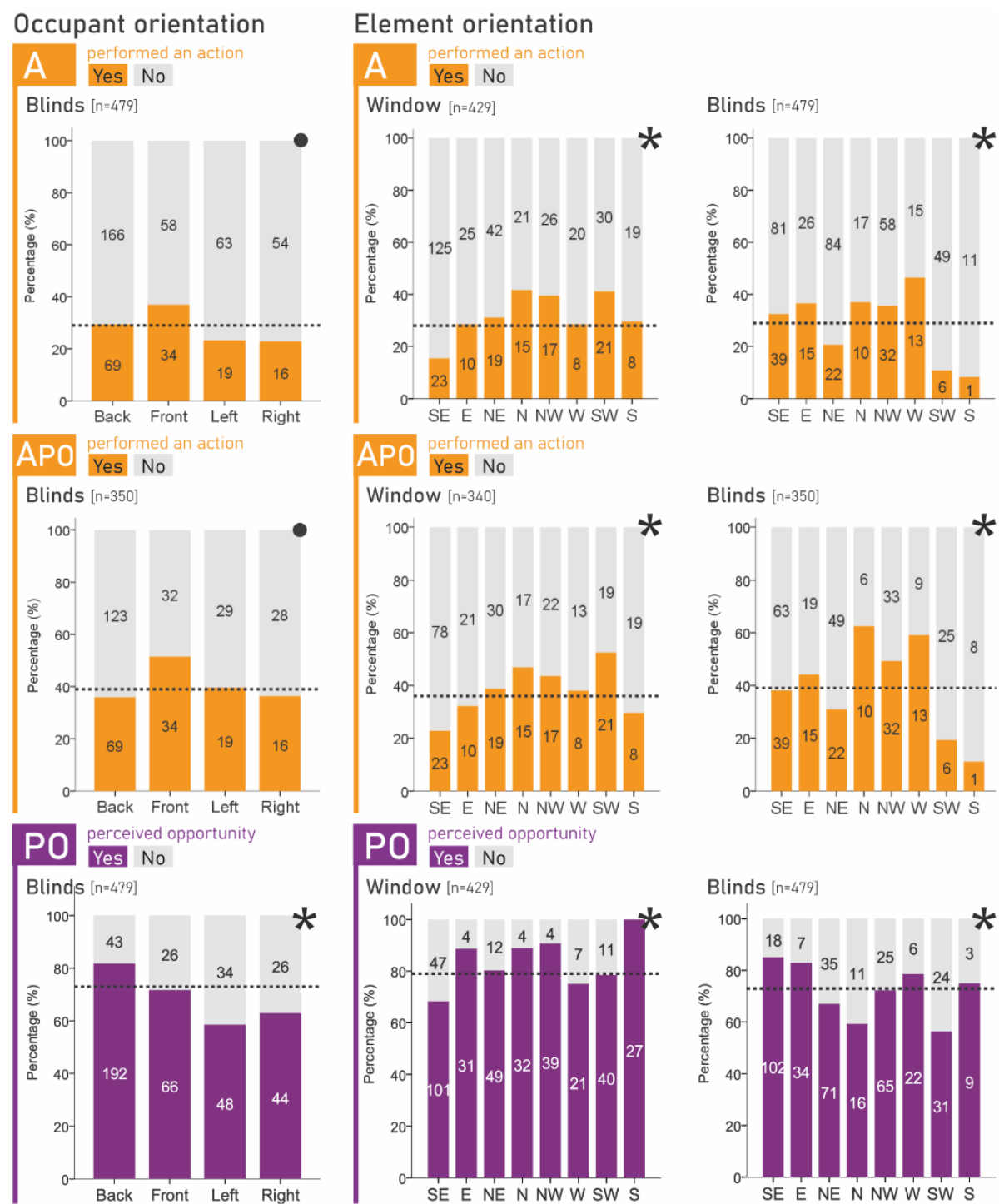

\section{PO perceived opportunity}
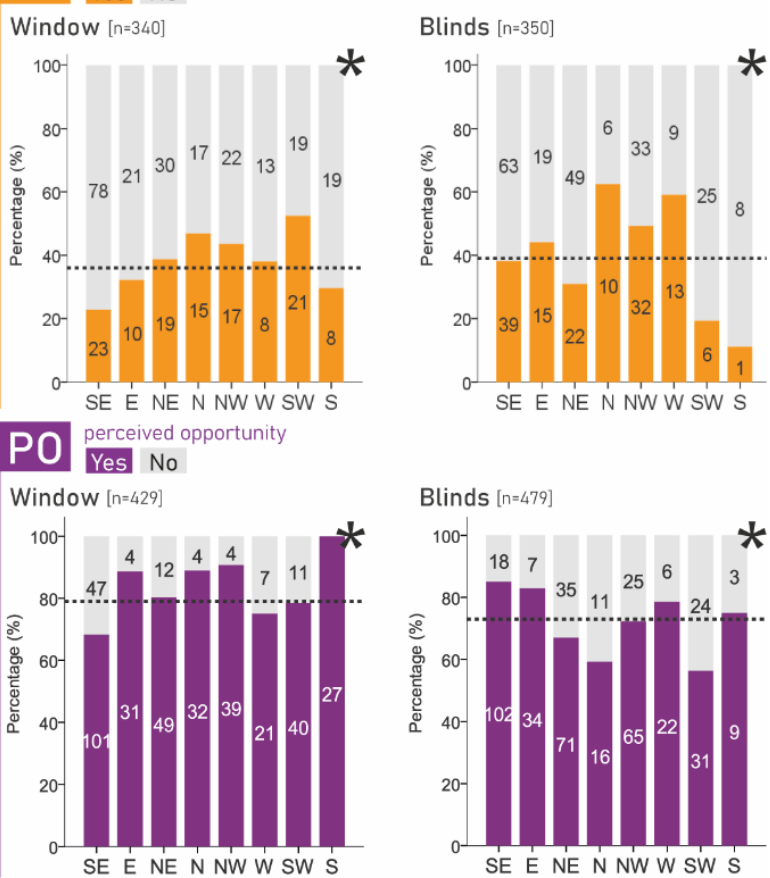

Figure 6. Proportion of occupants that operate the element indicated (A, APO) or that perceived opportunity (PO), by occupant orientation (left) and closest element orientation (right). The dashed line indicates the general proportion, presented in Table 5. The number in the bar indicates the total number of occupants. The graphs marked with a star show statistically significant relationships, while graphs with a circle show no-significant relationship but small-medium effect size. 
Table 8 summarises the mean distance to the element and differentiates those who performed an action and those who did not (A and APO sets), and those who perceived opportunity and those who did not (PO). The difference between those occupants was found to be highly significant for all the sets, showing a clear pattern. Overall, the occupants who operated the elements (windows and blinds) are located closer to them than those that did not act.

\begin{tabular}{|c|c|c|c|c|c|c|c|}
\hline \multirow[b]{2}{*}{ Element } & \multirow[b]{2}{*}{ Set } & \multicolumn{2}{|c|}{ Mean distance (SE) } & \multirow{2}{*}{$\begin{array}{c}\text { Difference } \\
\text { [BCa 95\% CI] }\end{array}$} & \multirow[b]{2}{*}{ Statistical test ${ }^{*}$} & \multirow[b]{2}{*}{ p-value } & \multirow[b]{2}{*}{ Effect size $e^{* * *}$} \\
\hline & & Yes & No & & & & \\
\hline \multirow[t]{3}{*}{ Window } & $\mathrm{A}$ & $2.25 \mathrm{~m}(0.17)$ & $4.17 \mathrm{~m}(0.25)$ & $1.92 \mathrm{~m}[1.36,2.53]$ & $t(422.89)=6.37$ & $<0.001$ & 0.57 \\
\hline & $\mathrm{APO}$ & $2.25 \mathrm{~m}(0.17)$ & $3.07 \mathrm{~m}(0.20)$ & $0.82 \mathrm{~m}[0.34,1.29]$ & $t(327.35)=3.18$ & 0.002 & 0.34 \\
\hline & $\mathrm{PO}$ & $2.78 \mathrm{~m} \mathrm{(0.15)}$ & $6.87 \mathrm{~m}(0.59)$ & $4.10 \mathrm{~m}[3.04,5.31]$ & $t(96.916)=6.35$ & $<0.001$ & 0.89 \\
\hline \multirow[t]{3}{*}{ Blinds } & $\mathrm{A}$ & $1.82 \mathrm{~m}(0.13)$ & $3.46 \mathrm{~m}(0.14)$ & $1.63 \mathrm{~m}[1.22,2.02]$ & $t(406.504)=8.60$ & $<0.001$ & 0.78 \\
\hline & $\mathrm{APO}$ & $1.82 \mathrm{~m}(0.13)$ & $2.80 \mathrm{~m}(0.14)$ & $0.98 \mathrm{~m}[0.59,1.36]$ & $t(340.017)=5.11$ & $<0.001$ & 0.54 \\
\hline & $\mathrm{PO}$ & $2.42 \mathrm{~m} \mathrm{(0.10)}$ & $4.53 \mathrm{~m}(0.26)$ & $2.12 \mathrm{~m}[1.63,2.65]$ & $t(170.478)=67.699$ & $<0.001$ & 0.86 \\
\hline
\end{tabular}

A: Action, APO: Action+Perceived Opportunity, PO: Perceived Opportunity

* Statistical test: $t$-test for independence. Df are indicated in brackets.

** $\mathrm{p}$-values in bold are statistically significant $(\mathrm{p}<0.05)$.

${ }^{* * *}$ Effect size is Cohen's d. Effect size indicates the strength of relationship where 0.1: small, 0.3: medium, 0.5: large.

381 The proportion of occupants that performed an action according to their distance from the closest window and blinds is presented in Figure 7. Although the relationship does not seem to be constant, thereby suggesting the influence of other factors, there is an observable trend that coincides as expected: the shorter the distance to the control element, the greater the proportion of occupants that interact with it. The same trend exists regarding the perception of opportunity: in general, the greater the distance, the lower the proportion of occupants that declared having an opportunity. The graph includes the logistic regression curves showing the predicted probabilities for A, APO and PO. 


\section{Distance}

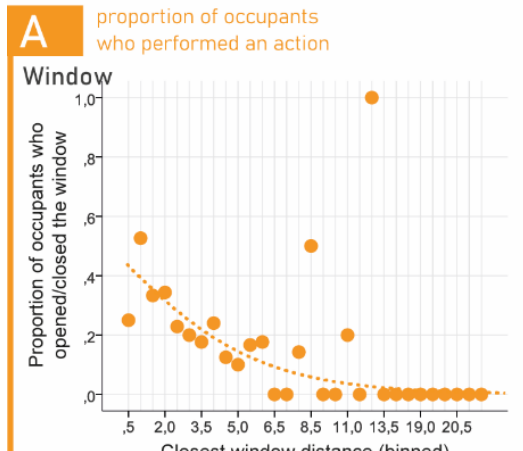

Closest window distance (binned)

\section{APO proportion of occupants}

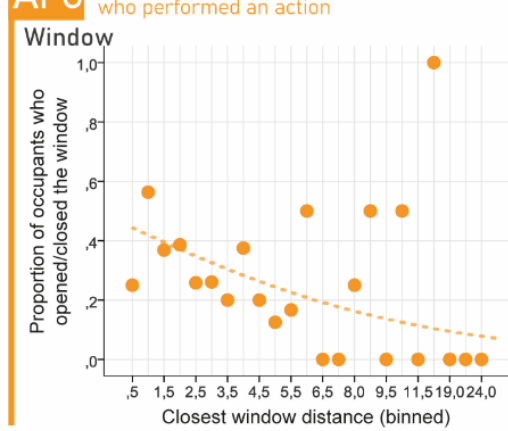

PO proportion of occupants

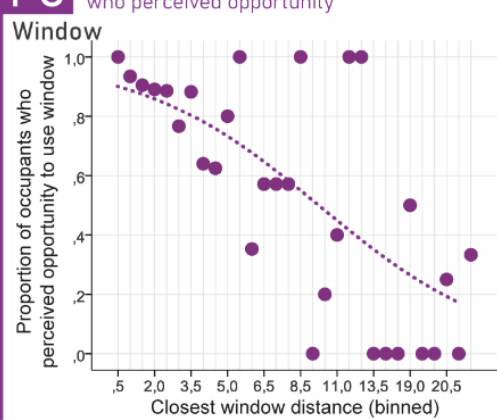

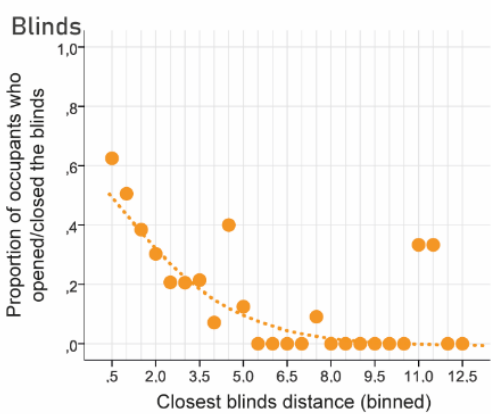

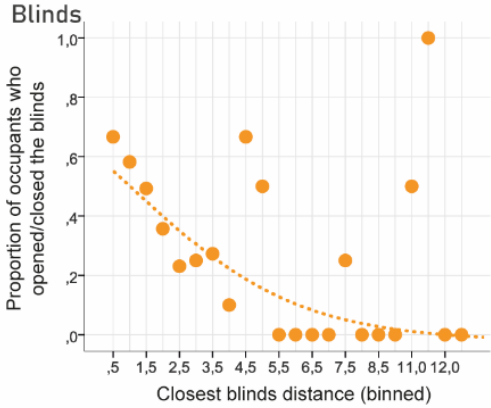

Closest blinds distance (binned)

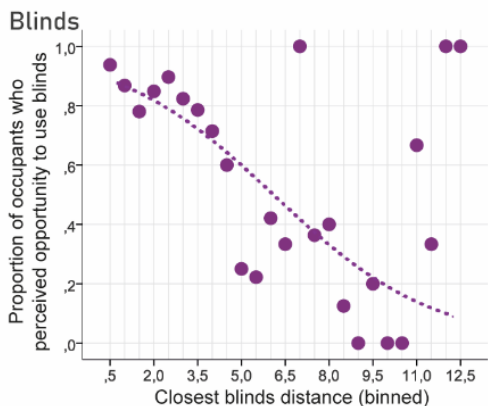

Figure 7. Observed proportion of occupants who opened/closed (A, APO) or perceived opportunity to do so (PO), based on occupant distance (binned $0.5 \mathrm{~m}$ ) to the element. The logistic regression curve showing the predicted probabilities is included.

The logistic regression showed a significant relationship both for the window and the blinds, although in the case of the former a distance was not identified at which an occupant is more likely to be active. For the blinds, this distance was $0.5 \mathrm{~m}$ for the A set, and $0.1 \mathrm{~m}$ for the APO. Regarding the distance and whether the occupant perceived having an opportunity or not, the two groups (yes or no) were clearly identified with a cut-off point of $9 \mathrm{~m}$ for the window and $6 \mathrm{~m}$ for the blinds. This means that at distances shorter than these values, it is more likely that the occupant will perceive they have an opportunity, while at longer distances, the chances are that they will perceive they do not. However, $\mathrm{R}^{2}$ was small and therefore these results should be interpreted with caution and further studies are required to validate these distances.

The parameters obtained in the logistic regression, as well as the odds ratio, which shows that the greater the distance the greater the probability that the occupant does not take action (A and APO sets), as well as the greater the distance, the higher the probability that the occupant perceive he or she does not have an opportunity, despite being in a space with the control element (PO), are presented in Table 9. 
Table 9. Coefficients for logistic regression models predicting whether an occupant performed an action (A-APO) or predicting whether an occupant perceived opportunity (PO) for the indicated control elements.

\begin{tabular}{|c|c|c|c|c|c|c|c|c|c|c|}
\hline & & Coefficien & [95\% BCa] & & $95 \%$ & I for Od & s Ratio & & mnibus test & \\
\hline Set & Element & Constant & Distance & $\begin{array}{l}\text { p-value } \\
\text { distance }\end{array}$ & Lower & $\begin{array}{l}\text { Odds } \\
\text { Ratio }\end{array}$ & Upper & $\mathbf{R}^{2 *}$ & Model & p-value \\
\hline$\overline{\mathrm{A}}$ & Window & $\begin{array}{c}-0.10 \\
{[-0.52,0.43]}\end{array}$ & $\begin{array}{c}-0.29 \\
{[-0.48,-0.18]}\end{array}$ & 0.001 & 0.66 & 0.75 & 0.85 & 0.11 & $\chi^{2}(1)=33.69$ & $\mathrm{p}<0.001$ \\
\hline & Blinds & $\begin{array}{c}0.31 \\
{[-0.18,0.93]}\end{array}$ & $\begin{array}{c}-0.50 \\
{[-0.75,-0.34]}\end{array}$ & 0.001 & 0.51 & 0.61 & 0.71 & 0.17 & $\chi^{2}(1)=62.15$ & $\mathrm{p}<0.001$ \\
\hline $\mathrm{APO}$ & Window & $\begin{array}{c}-0.11 \\
{[-0.52,0.47]}\end{array}$ & $\begin{array}{c}-0.19 \\
{[-0.41,-0.06]}\end{array}$ & 0.032 & 0.73 & 0.83 & 0.95 & 0.04 & $\chi^{2}(1)=10.14$ & $\mathrm{p}<0.001$ \\
\hline & Blinds & $\begin{array}{c}0.46 \\
{[-0.07,1.15]}\end{array}$ & $\begin{array}{c}-0.41 \\
{[-0.72,-0.19]}\end{array}$ & 0.003 & 0.56 & 0.67 & 0.8 & 0.10 & $\chi^{2}(1)=27.54$ & $\mathrm{p}<0.001$ \\
\hline $\mathrm{PO}$ & Window & $\begin{array}{c}2.38 \\
{[1.98,2.95]}\end{array}$ & $\begin{array}{c}-0.26 \\
{[-0.38,-0.18]}\end{array}$ & 0.001 & 0.72 & 0.78 & 0.84 & 0.22 & $\chi^{2}(1)=65.81$ & $\mathrm{p}<0.001$ \\
\hline & Blinds & $\begin{array}{c}2.16 \\
{[1.80,2.61]}\end{array}$ & $\begin{array}{c}-0.35 \\
{[-0.48,-0.25]}\end{array}$ & 0.001 & 0.64 & 0.7 & 0.77 & 0.19 & $\chi^{2}(1)=68.20$ & $\mathrm{p}<0.001$ \\
\hline
\end{tabular}

* Nagelkerke's R ${ }^{2}$

\subsubsection{Gender and age range}

Figure 8 shows the distribution of the occupants by gender and differentiates if they perform an action or perceived the opportunity to operate the elements were a relationship was found. Men used less the window and personal devices than women. More women perceived not having an opportunity to operate a thermostat than men, when in fact they do.

According to age, those who least operate blinds and personal devices are the youngest. This changes in the APO set for personal devices, where the ones that interact most are precisely the young. This would suggest that once this group recognizes their opportunity, they take advantage of it. Likewise, the probability of perceiving the opportunity varies according to age. The younger the occupant, the more likely they perceive they cannot modify their environment. This trend can be identified in Figure 9 and applies for all control elements. Particularly, there are always fewer occupants than expected who are under age 26 and perceived opportunity.
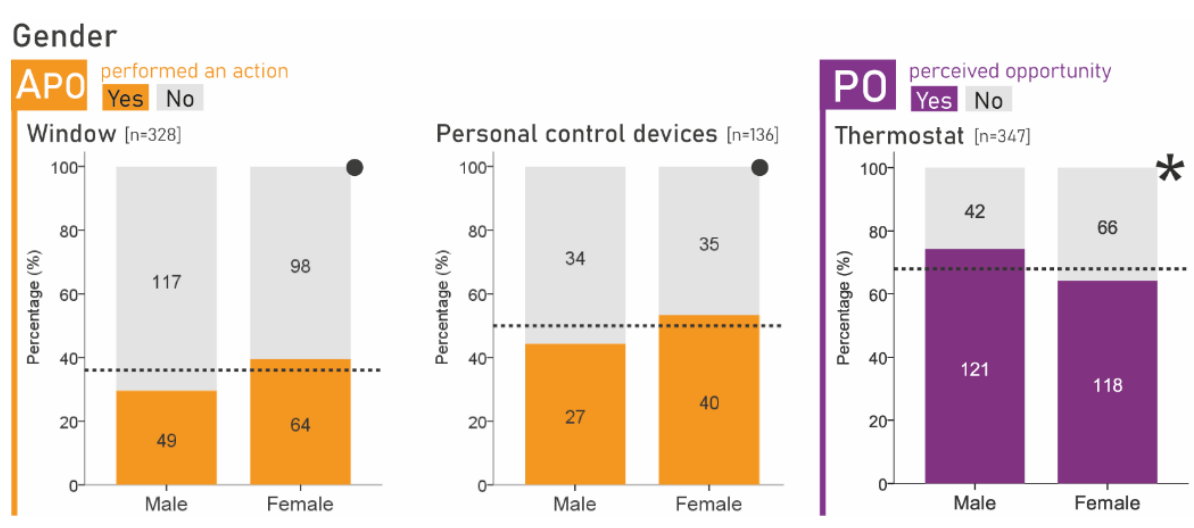

Figure 8. The proportion of occupants that perform an action (A) or perceived opportunity (PO) by gender. The dashed line indicates the general proportion, presented in Table 5. The number in the bar indicates the total number of occupants. The graphs marked with a star show statistically significant relationships, while graphs with a circle show no-significant relationship but small-medium effect size. 

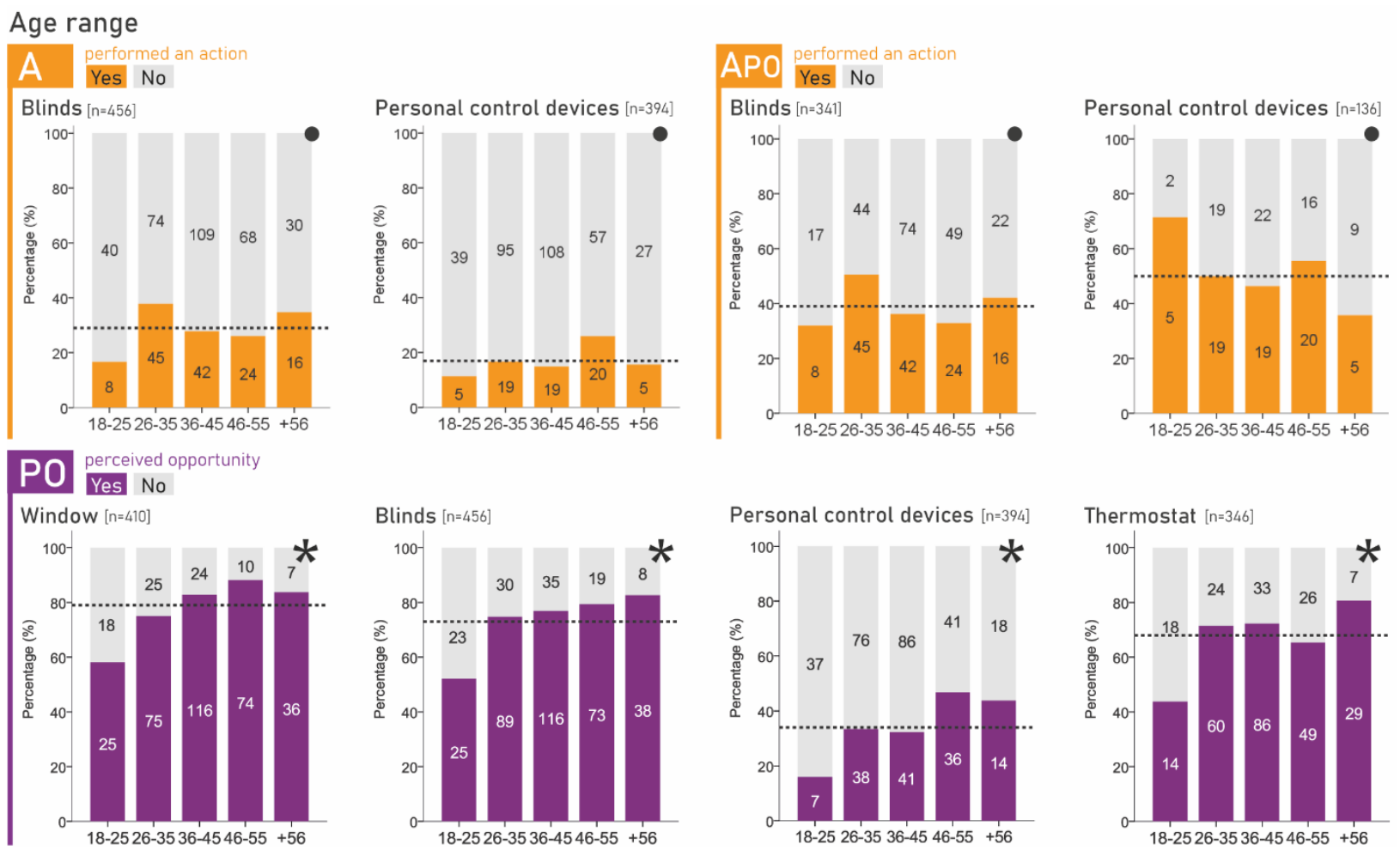

Figure 9. The proportion of occupants that perform an action (A and APO) or perceived opportunity (PO) by age range. The dashed line indicates the general proportion, presented in Table 5. The number in the bar indicates the total number of occupants.

The graphs marked with a star show statistically significant relationships, while graphs with a circle show no-significant relationship but small-medium effect size.

\section{Discussion}

The results from this field study show the relationship between some spatial and human factors and the performance of actions. The relationship between these factors and the perceived opportunity to use a control element was also studied. In fact, the findings suggest that the spatial and human factors are more related to whether the occupant perceived having an opportunity than if they performed an action. However, given that perceived opportunity is essential for being active, these factors indirectly influence if the occupant acts or not.

It is worth mentioning that the relationship between whether an occupant performed an action or not and the perceived opportunity was found to be significant (window: $\chi^{2}(1, n=429)=41.048, p<0.001$; blinds: $\chi^{2}(1$, $n=479)=71.447, p<0.001$; device: $\chi^{2}(1, n=413)=165.399, p<0.001$; thermostat: $\left.\chi^{2}(1, n=361)=25.551, p<0.001\right)$. These findings match those observed in previous studies which suggest that as perceived control increases, the use of control elements also rises [25]. This reflects the important role of perceived opportunity or perceived control over the elements of the building in determining whether an occupant acts.

The data presented and the analysis sets made it possible to study not only the characteristics of the occupants who performed an action (the active ones) but also those who did not (the passive occupants). The latter could be divided into two groups based on the findings: the occupants that perceived they have the opportunity to perform the action but did not, which could be called "passive by choice" since for some reason they chose not to act; and their counterparts would therefore be the "passive by obligation" 
occupants, those who declared they do not have the opportunity to use a control element even though it exists in their office space, which suggests that these occupants consider themselves unable to act.

Regarding the active occupants, represented by the characteristics of the A set, the results indicate that the factors most related to occupants being active are the spatial layout, distance from the element, and element orientation. On the contrary, occupant orientation in relation to an element, gender, and age range do not appear to be associated with an occupant performing an adaptive environmental action. Mainly, the occupants who perform an action are those who are closer to the elements and those who are next to elements facing facades with high solar exposure. Being in a shared space decreases the probability that an occupant will perform an action.

Furthermore, as the APO set analysis suggests, there are more "passive by choice" occupants in shared spaces. It also indicates that they are slightly farther away from control elements and they are associated with elements with low solar exposure. Gender and age do not appear to be related to whether an occupant decides to act, once he or she recognizes they have the opportunity to adjust the indoor environment.

Overall, spatial layout, distance and age are influencing factors for perceiving opportunity. By analysing the PO set, it was found that there are more "passive by obligation" occupants in shared spaces and that they are far from the control element. Likewise, these occupants are more likely to be young and in the case of the thermostat, women. Regarding the blinds, if they are located to the side of the occupants, it is more likely that the occupants perceive not having control over this element.

The main findings are summarized below by studied factor and are contrasted with the related literature. As mentioned in the literature review, there are a number of studies about spatial and human factors regarding satisfaction with the indoor environment and thermal comfort, but research on the influence of these factors on the performance of the actions is scarce. Moreover, most studies only mention the relationship, few studies present patterns or explicitly describe the relationship, and as far as is known, none address the occupants' specific position. Some studies address the influence of perceived control on satisfaction with IEQ and comfort, but there are few that integrate and link it with the performance of the action.

\subsection{Spatial layout}

The relationship between spatial layout and use of the window, blinds or thermostat was found to be highly significant. Proportionally, there are more active occupants in individual offices than in shared. This finding is consistent with previous studies for windows and blinds [48,49], and gives new insights for thermostat and personal control device usage. This makes sense if it is understood that in shared spaces, the availability of controls is limited, and it might not be necessary or possible for all of the occupants to perform an action. In addition, spatial layout was found to be related with the perceived opportunity of use for all the control elements. Occupants in shared spaces, particularly open spaces, 
perceived they do not have opportunity, when they in fact they do. This is in line with Schweiker and Wagner [48] who found that perceived control of windows and blinds was negatively affected by the number of people in an experimental study.

The use of personal fans or heaters had an interesting inverse pattern, with more active occupants in shared than in individual spaces. This was not statistically significant but rather represents a small effect size, worthy of further investigation. This could suggest that in shared spaces occupants depend more on personal adaptations, thus supporting the idea of personal comfort models [76].

Moreover, it was found that when considering only those occupants who perceived opportunity (APO set), the relationship between spatial layout and blind operation was no longer significant, though it had a small effect size. This could suggest that in the case of blinds, this relationship might be directly associated with the perceived opportunity. Since the relationship remains significant for windows and thermostats, more analysis is required to identify how spatial layout influences the interaction with these elements.

These findings could indicate that social factors like coexistence could limit adaptive actions in shared spaces, as a result of affecting the perceived opportunity. Hence, dynamics in these kinds of spaces and especially the thermal comfort of occupants should be further explored to identify the specific factors that cause spatial layout to be related to whether the occupant is active or not, as it has been found that spatial layout is related with IEQ satisfaction and thermal comfort [39,42,74]. Both of them are higher in individual offices than open offices $[39,41,77]$.

\subsection{Occupants' orientation}

In relation to blinds, occupant orientation was associated with perceived opportunity but not with the performance of actions. However, effect sizes were between small and medium, suggesting that further investigation is necessary. Concerning action, a possible trend was observed: occupants with blinds in front of them are more likely to use them. Regarding perceived opportunity, it was greater when blinds are behind the occupant and less when to the left or right. This could be associated with factors such as glare and reflected light directly on the occupants' screens. These are primary reasons to use the blinds according to Inkarojrit [78], in addition to solar radiation on occupants' backs, which could cause the need for the element and therefore its recognition within the space. There are numerous studies regarding blinds that mainly address the relationship with building orientation, which results in solar radiation. However, in reviewing the literature no data was encountered describing occupants' orientation and opportunity perception, although it has been found that orientation could impact the use of blinds [37] and visual and thermal comfort $[47,79]$.

Regarding the windows, surprisingly, no relationship was observed either for the performance of the action or the perception of opportunity based on the occupants' orientation. There were no differences 
between those with the window in front or back, or to the left or right side. This is of interest for design and suggests that it does not matter where desks are located regarding windows; the occupant will act or will perceive opportunity based on other factors.

\subsection{Element orientation}

In Concepción $\left(36^{\circ} \mathrm{S}\right)$, windows and blinds facing north are subject to greater solar radiation throughout the entire year; the windows in this orientation had the highest proportion of associated active occupants. This is consistent with previous studies which found that a higher solar radiation is related to a greater proportion of open windows $[80,81]$. The windows facing southeast had the least associated active occupants, which could be explained by the fact that the little solar exposure this facade receives occurs in the morning, as is the case with blinds that receive less solar radiation [46,82].

In the case of the blinds, those that are located facing west registered the most active occupants, which could be linked to the search for protection from solar radiation in the afternoon. These results agree with the findings of other studies, which report that the facade with greater solar exposure in the afternoon, due to lower solar altitude and deeper solar penetration, causes increased closing of the blinds $[83,84]$. The active occupants are more in concordance with the blind closing pattern previously identified in other contexts $[47,48]$ : they increase according to the sun's movement and possible heat gains during the day.

\subsection{Distance}

Distance has scarcely been studied as an influencing factor for the performance of actions, since most of the previous research has been carried out in offices with the same characteristics and thus distance was not a distinctive factor. It was found to be highly related both with the performance of the action and the perceived opportunity. Overall, the shorter the distance, the greater the probability of being active or perceiving the opportunity. The logistic regressions done give an idea of what those distances could be. However, since the model is incomplete, all spatial layouts are included and have a low $\mathrm{R}^{2}$, further research is needed to validate the distances and integrate other factors.

It is worth to noting that the average distance values of those who perform an action and those who do not decrease in the A set, thus suggesting that the relationship between distance and action could be a reflection of the effect of distance on the perception of opportunity.

\subsection{Gender}

The results suggest that gender does not influence whether the occupant decides to perform an action or not. These results are consistent with Andersen et al. [23] regarding blinds and heating, and they are opposite to Schweiker and Shukuya [58] and Karjalainen [59], who found that males use thermostats more often than females, though their studies were in residences. Nevertheless, a small-medium effect size was found for window and personal control devices, thereby indicating that women are slightly more active than men, which is in line with Andersen et al. [23]. This trend is worthy of additional research. 
Alternately, surprisingly, it was discovered that only gender is significantly associated with the perception of thermostat control. It is more likely that a woman perceives not having an opportunity, when in fact she does. A similar finding was reported by Karjalainen [59] in offices in Finland.

\subsection{Age range}

According to previous studies $[23,85]$, age is an important characteristic in determining energy use. However, this study was unable to demonstrate that age influences the performance of actions. The relationship between age range and interaction with windows and thermostats was not found to be significant, in agreement with Karjalainen [59]. This relationship was also not significant regarding the use of blinds and personal control devices. Nonetheless, the last two had a small-medium effect size that would suggest this relationship could exist and should be investigated in future research. For the blinds, younger people interacted less, while for the personal devices (fans or heaters) the trend was the opposite, thereby showing that younger people depend more on personal adaptation.

Interestingly, this last trend is the same regarding the perceived opportunity for all the control elements. The younger the occupant, the more likely they perceive they cannot use the control element. This could be due to a social factor associated with these occupants: they may not have the confidence to make changes in an environment, especially if it is shared. They could feel they do not have the authority to make the decision for others or they may also have worked less time in the office, although these are only speculations and should be explored in future research.

\subsection{Limitations and future work}

It is important to highlight that this study addresses occupant behaviour from the perspective of the occupant, and the probability that occupants are active or passive depending on spatial or human factors, as well as the influence of those factors on perceived opportunity. Case selection was purposive and based on institutional availability. Thus, random case or occupant selection was not possible, even though this coincides with other studies of this type $[86,87]$. Each office space was surveyed for one day in each season, and the occupant responses were considered to be representative, keeping in mind that in these kinds of spaces many of the actions and particularly those who carry them out, tend to be constant in time. According to the scope of this research, a more intensive survey was not necessary, and indeed it would not be possible for logistical reasons and occupants' availability. Nevertheless, occupant classification was simplified for analysis purposes and findings should be validated considering the effect of environmental and time-related factors. When possible, subsequent studies could consider monitoring for more days to obtain a more precise occupant classification and not limit the inclusion of "occasional" active occupants.

With regard to recording the actions, this study was based on information provided by the occupants through surveys which could be subject to self-reporting bias. To minimize this, the survey was done faceto-face and observations in the field were made regarding the available control elements. Likewise, the grouping of the questionnaires answered by the same participant, allowed unifying their profile and 
avoiding potential errors in their isolate answers. It is important to note that just like other studies using surveys $[22,23]$, this research aimed to identify patterns, rather than monitor the actions.

Similarly, following the idea that people carry out the actions that are easier for them $[31,88]$, the element the occupant has an opportunity to operate was considered to be the one closest to him or her. However, there is no certainty as to if this was the element that was operated, and future studies dealing with multiple occupants should record the control elements linked to each occupant. These results therefore need to be interpreted with caution. For a more precise representation of actions and spatial factors, it would be interesting to evaluate the effect of the presence of other individuals between the occupant and the control elements.

Lastly, this article presents the patterns associated with the spatial and occupant factors independently for each variable studied, as a first step for future studies where these factors could be integrated into a multivariable model that addresses their relationships and facilitates their application in the design process. Other factors should also be considered, including diversity [89-91]. Human behaviour is complex and varied, and it may not be perfectly represented in a statistical model. However, with a better understanding of it, it is hoped to optimize designs and use of the built environment [92-94].

\section{Conclusions}

The results presented suggest that the probability that an action occurs is different depending on spatial and human factors. At the same time, this research addresses the influence of group dynamics on the use of element controls in shared offices, through fieldwork. Likewise, it presents the relationship between the position of an occupant and their actions. In shared spaces, there are fewer active occupants, and those who interact with elements depend on the perception of opportunity that they have, which is particularly associated with the spatial layout and the occupant's age. The closer an occupant is to an element, the more likely he or she is to interact with it, and the younger the occupant, the less likely that he or she is to do so since this condition restricts the occupant's perception of opportunity. It is essential that occupants perceive they have an opportunity so they can be active. Spatial and human factors are more related to the perception of opportunity than with the performance of the action itself, although some of the factors seem to function effectively as facilitators or limiters of actions.

While the goal is not for all occupants to perform all the actions, it is of interest to inquire how to encourage the occurrence of the actions and seek better performance in buildings from an architectural point of view. To this end, it is necessary to know the characteristics of those who carry out the actions so that there can be a degree of certainty that the actions expected during the design phase do actually occur.

Alternately, integrating this study into the probability models that determine whether an action occurs or not could contribute by generating an adjustment factor for the models based on environmental and/or time-related factors. The latter act as predictors and could be complemented with the occupant's spatial 

also to architectural and interior design strategies that promote more active occupants.

\section{Acknowledgements}

This research was conducted as part of Fondecyt Project 1171497: Buildings don't consume energy, people do. Adaptive thermal comfort criteria for the architectural design of offices in Chile. In addition, we would like to acknowledge the research group, $194503 \mathrm{GI} / \mathrm{C}$ "Confort ambiental y pobreza energética (+CO-PE)", of the Universidad del Bío-Bío for supporting this research.

\section{References}

[1] D. Yan, W. O'Brien, T. Hong, X. Feng, H.B. Gunay, F. Tahmasebi, A. Mahdavi, Occupant behavior modeling for building performance simulation: Current state and future challenges, Energy and Buildings. 107 (2015) 264-278. doi:10.1016/j.enbuild.2015.08.032.

[2] H. Polinder, M. Schweiker, V.D.A. Ad, K. Schakib-Ekbatan, V. Fabi, R.K. Andersen, N. Morishita, C. Wang, S.P. Corgnati, P. Heiselberg, D. Yan, B.W. Olesen, T. Bednar, A. Wagner, Separate Document Volume II Annex 53 - Occupant behavior and modeling, (2013) 153.

[3] D. Yan, T. Hong, Definition and Simulation of Occupant Behavior in Buildings. Annex 66 Final Report, The Regents of the University of California (through Lawrence Berkeley National Laboratory) and Tsinghua University, China, 2018.

[4] A.C. Menezes, A. Cripps, D. Bouchlaghem, R. Buswell, Predicted vs. actual energy performance of non-domestic buildings: Using post-occupancy evaluation data to reduce the performance gap, Applied Energy. 97 (2012) 355-364. doi:10.1016/j.apenergy.2011.11.075.

[5] A. Dasgupta, A. Prodromou, D. Mumovic, Operational versus designed performance of low carbon schools in England: Bridging a credibility gap, HVAC\&R Research. 18 (2012) 37-41. doi:10.1080/10789669.2011.614318.

[6] M. Herrando, D. Cambra, M. Navarro, L. de la Cruz, G. Millán, I. Zabalza, Energy Performance Certification of Faculty Buildings in Spain: The gap between estimated and real energy consumption, Energy Conversion and Management. in press (2016) 141-153. doi:doi:10.1016/j.enconman.2016.04.037.

[7] S. D'Oca, T. Hong, J. Langevin, The human dimensions of energy use in buildings: A review, Renewable and Sustainable Energy Reviews. 81 (2018) 731-742. doi:10.1016/j.rser.2017.08.019.

[8] S. D'Oca, C. Chen, T. Hong, Z. Belafi, Synthesizing building physics with social psychology: An interdisciplinary framework for context and occupant behavior in office buildings, Energy Research \& Social Science. 34 (2017) $240-251$. doi:10.1016/j.erss.2017.08.002.

[9] W. O'Brien, I. Gaetani, S. Carlucci, P.-J. Hoes, J.L.M. Hensen, On occupant-centric building performance metrics, Building and Environment. 122 (2017) 373-385. doi:10.1016/j.buildenv.2017.06.028.

[10] O. Guerra-Santin, L. Itard, H. Visscher, The effect of occupancy and building characteristics on energy use for space and water heating in Dutch residential stock, Energy and Buildings. 41 (2009) 1223-1232. doi:10.1016/j.enbuild.2009.07.002.

[11] I. Gaetani, P.-J. Hoes, J.L.M. Hensen, On the sensitivity to different aspects of occupant behaviour for selecting the appropriate modelling complexity in building performance predictions, Journal of Building Performance Simulation. 1493 (2016) 1-11. doi:10.1080/19401493.2016.1260159.

[12] C. Piselli, A.L. Pisello, Occupant behavior long-term continuous monitoring integrated to prediction models: Impact on office building energy performance, Energy. 176 (2019) 667-681. doi:10.1016/j.energy.2019.04.005.

[13] F. Nicol, M.A. Humphreys, S. Roaf, Adaptive thermal comfort. Principles and practice, 1st ed., Routledge, Abingdon, 2012.

[14] W. O’Brien, S. Gilani, M.M. Ouf, Advancing Occupant Modeling for Building Design and Code Compliance: Part 1, (2019).

[15] M.A.R. Lopes, C.H. Antunes, A. Reis, N. Martins, Estimating energy savings from behaviours using building performance simulations, Building Research \& Information. 3218 (2016) 1-17. doi:10.1080/09613218.2016.1140000.

[16] O. Guerra-Santin, Relationship Between Building Technologies, Energy Performance and Occupancy in Domestic Buildings., in: D. Keyson, O. Guerra-Santin, D. Lockton (Eds.), Living Labs. Design and Assessment of Sustainable Living, 1st ed., Springer International Publishing Switzerland, 2017: pp. 333-344.

[17] M. Schweiker, S. Carlucci, R.K. Andersen, B. Dong, W. O’Brien, Occupancy and Occupants' Actions, in: A. Wagner, W. O’Brien, B. Dong (Eds.), Exploring Occupant Behavior in Buildings: Methods and Challenges, 1st ed., Springer, 2018: pp. 7- 
[18] W. O'Brien, A. Wagner, J.K. Day, Introduction to Occupant Research Approaches, in: A. Wagner, W. O'Brien, B. Dong (Eds.), Exploring Occupant Behavior in Buildings: Methods and Challenges, 1st ed., Springer, 2018: pp. 1-310. doi:10.1007/978-3319-61464-9.

[19] A. Heydarian, B. Becerik-Gerber, Use of immersive virtual environments for occupant behaviour monitoring and data collection, Journal of Building Performance Simulation. 10 (2017) 484-498. doi:10.1080/19401493.2016.1267801.

[20] A. Wagner, W. O'Brien, B. Dong, In Situ Approaches to Studying Occupants, in: Exploring Occupant Behavior in Buildings: Methods and Challenges, Springer, Cham, SWITZERLAND, 2018.

[21] P.F. Pereira, N.M.M. Ramos, Detection of occupant actions in buildings through change point analysis of in-situ measurements, Energy and Buildings. 173 (2018) 365-377. doi:10.1016/j.enbuild.2018.05.050.

[22] U. Wilke, F. Haldi, J.L. Scartezzini, D. Robinson, A bottom-up stochastic model to predict building occupants' timedependent activities, Building and Environment. 60 (2013) 254-264. doi:10.1016/j.buildenv.2012.10.021.

[23] R.V. Andersen, J. Toftum, K.K. Andersen, B.W. Olesen, Survey of occupant behaviour and control of indoor environment in Danish dwellings, Energy and Buildings. 41 (2009) 11-16. doi:10.1016/j.enbuild.2008.07.004.

[24] F. Haldi, D. Robinson, On the behaviour and adaptation of office occupants, Building and Environment. 43 (2008) 21632177. doi:10.1016/j.buildenv.2008.01.003.

[25] G.Y. Yun, K. Steemers, N. Baker, Natural ventilation in practice: Linking facade design, thermal performance, occupant perception and control, Building Research \& Information. 36 (2008) 608-624. doi:10.1080/09613210802417241.

[26] T. Hong, S. D'Oca, W.J.N. Turner, S.C. Taylor-Lange, An ontology to represent energy-related occupant behavior in buildings. Part I: Introduction to the DNAs framework, Building and Environment. 92 (2015) 764-777. doi:10.1016/j.buildenv.2015.08.006.

[27] V. Fabi, R.V. Andersen, S.P. Corgnati, B.W. Olesen, Occupants' window opening behaviour: A literature review of factors influencing occupant behaviour and models, Building and Environment. 58 (2012) 188-198. doi:10.1016/j.buildenv.2012.07.009.

[28] F. Stazi, F. Naspi, M. D'Orazio, A literature review on driving factors and contextual events influencing occupants' behaviours in buildings, Building and Environment. 118 (2017) 40-66. doi:10.1016/j.buildenv.2017.03.021.

[29] S. Pan, Y. Xiong, Y. Han, X. Zhang, L. Xia, S. Wei, J. Wu, M. Han, A study on influential factors of occupant window-opening behavior in an office building in China, Building and Environment. 133 (2018) 41-50. doi:10.1016/j.buildenv.2018.02.008.

[30] B. Dong, D. Yan, Z. Li, Y. Jin, X. Feng, H. Fontenot, Modeling occupancy and behavior for better building design and operation-A critical review, Building Simulation. 11 (2018) 899-921. doi:10.1007/s12273-018-0452-x.

[31] W. O'Brien, H.B. Gunay, The contextual factors contributing to occupants' adaptive comfort behaviors in offices - A review and proposed modeling framework, Building and Environment. 77 (2014) 77-88. doi:10.1016/j.buildenv.2014.03.024.

[32] E. Delzendeh, S. Wu, A. Lee, Y. Zhou, The impact of occupants' behaviours on building energy analysis: A research review, Renewable and Sustainable Energy Reviews. 80 (2017) 1061-1071. doi:10.1016/j.rser.2017.05.264.

[33] M. Schweiker, M. Hawighorst, A. Wagner, The influence of personality traits on occupant behavioural patterns, Energy and Buildings. 131 (2016) 63-75. doi:10.1016/j.enbuild.2016.09.019.

[34] A. Rinaldi, M. Schweiker, F. Iannone, On uses of energy in buildings: Extracting influencing factors of occupant behaviour by means of a questionnaire survey, Energy and Buildings. 168 (2018) 298-308. doi:10.1016/j.enbuild.2018.03.045.

[35] A.C. Boerstra, M. te Kulve, J. Toftum, M.G.L.C. Loomans, B.W. Olesen, J.L.M. Hensen, Comfort and performance impact of personal control over thermal environment in summer: Results from a laboratory study, Building and Environment. 87 (2015) 315-326. doi:10.1016/j.buildenv.2014.12.022.

[36] J.K. Day, J. Theodorson, K. Van Den Wymelenberg, Understanding controls, behaviors and satisfaction in the daylit perimeter office: A daylight design case study, Journal of Interior Design. 37 (2012) 17-34. doi:10.1111/j.19391668.2011.01068.x.

[37] D. Maniccia, B. Rutledge, M.S. Rea, W. Morrow, Occupant use of manual lighting controls in private offices, Journal of the Illuminating Engineering Society. 28 (1999) 42-56. doi:10.1080/00994480.1999.10748274.

[38] X. Zhou, T. Liu, X. Shi, X. Jin, Case study of window operating behavior patterns in an open-plan office in the summer, Energy and Buildings. 165 (2018) 15-24. doi:10.1016/j.enbuild.2018.01.037.

[39] M. Kwon, H. Remøy, M. van den Bogaard, M. Van Den Bogaard, Influential design factors on occupant satisfaction with indoor environment in workplaces, Building and Environment. 157 (2019) 356-365. doi:10.1016/j.buildenv.2019.05.002.

[40] M. Awada, I. Srour, A genetic algorithm based framework to model the relationship between building renovation decisions 
and occupants' satisfaction with indoor environmental quality, Building and Environment. 146 (2018) $247-257$. doi:10.1016/j.buildenv.2018.10.001.

[41] M. Frontczak, S. Schiavon, J. Goins, E. Arens, H. Zhang, P. Wargocki, Quantitative relationships between occupant satisfaction and satisfaction aspects of indoor environmental quality and building design, Indoor Air. 22 (2012) 119-131. doi:10.1111/j.1600-0668.2011.00745.x.

[42] P.M. Bluyssen, M. Aries, P. van Dommelen, Comfort of workers in office buildings: The European HOPE project, Building and Environment. 46 (2011) 280-288. doi:10.1016/j.buildenv.2010.07.024.

[43] S. Schiavon, S. Altomonte, Influence of factors unrelated to environmental quality on occupant satisfaction in LEED and non-LEED certified buildings, Building and Environment. 77 (2014) 148-159. doi:10.1016/j.buildenv.2014.03.028.

[44] Z. Kong, D.M. Utzinger, K. Freihoefer, T. Steege, The impact of interior design on visual discomfort reduction: A field study integrating lighting environments with POE survey, Building and Environment. 138 (2018) 135-148. doi:10.1016/j.buildenv.2018.04.025.

[45] F. Mofidi, H. Akbari, An integrated model for position-based productivity and energy costs optimization in offices, Energy and Buildings. 183 (2019) 559-580. doi:10.1016/j.enbuild.2018.11.009.

[46] C.F. Reinhart, V. K., Monitoring manual control of electric lighting and blinds, Lighting Research and Technology. 35 (2003) 243-260.

[47] K. Van Den Wymelenberg, Patterns of occupant interaction with window blinds: A literature review, Energy and Buildings. 51 (2012) 165-176. doi:10.1016/j.enbuild.2012.05.008.

[48] M. Schweiker, A. Wagner, The effect of occupancy on perceived control, neutral temperature, and behavioral patterns, Energy and Buildings. 117 (2016) 246-259. doi:10.1016/j.enbuild.2015.10.051.

[49] F. Haldi, D. Robinson, Adaptive actions on shading devices in response to local visual stimuli, Journal of Building Performance Simulation. 3 (2010) 135-153. doi:10.1080/19401490903580759.

[50] T. Hong, D. Yan, S. D'Oca, C. Chen, Ten questions concerning occupant behavior in buildings: The big picture, Building and Environment. 114 (2017) 518-530. doi:10.1016/j.buildenv.2016.12.006.

[51] F. Haldi, D. Robinson, On the unification of thermal perception and adaptive actions, Building and Environment. 45 (2010) 2440-2457. doi:10.1016/j.buildenv.2010.05.010.

[52] E. Sardianou, Estimating space heating determinants: An analysis of Greek households, Energy and Buildings. 40 (2008) 1084-1093. doi:10.1016/j.enbuild.2007.10.003.

[53] D. Mora, C. Carpino, M. De Simone, Behavioral and physical factors influencing energy building performances in Mediterranean climate, Energy Procedia. 78 (2015) 603-608. doi:10.1016/j.egypro.2015.11.033.

[54] B. Mills, J. Schleich, Residential energy-efficient technology adoption, energy conservation, knowledge, and attitudes: An analysis of European countries, Energy Policy. 49 (2012) 616-628. doi:10.1016/j.enpol.2012.07.008.

[55] J.K. Maykot, R.F. Rupp, E. Ghisi, A field study about gender and thermal comfort temperatures in office buildings, Energy and Buildings. 178 (2018) 254-264. doi:10.1016/j.enbuild.2018.08.033.

[56] M. Indraganti, K.D. Rao, Effect of age, gender, economic group and tenure on thermal comfort: A field study in residential buildings in hot and dry climate with seasonal variations, Energy and Buildings. 42 (2010) 273-281. doi:10.1016/j.enbuild.2009.09.003.

[57] M.S. Andargie, E. Azar, An applied framework to evaluate the impact of indoor office environmental factors on occupants' comfort and working conditions, Sustainable Cities and Society. 46 (2019) 101447. doi:10.1016/j.scs.2019.101447.

[58] M. Schweiker, M. Shukuya, Comparison of theoretical and statistical models of air-conditioning-unit usage behaviour in a residential setting under Japanese climatic conditions, Building and Environment. 44 (2009) 2137-2149. doi:10.1016/j.buildenv.2009.03.004.

[59] S. Karjalainen, Gender differences in thermal comfort and use of thermostats in everyday thermal environments, Building and Environment. 42 (2007) 1594-1603. doi:10.1016/j.buildenv.2006.01.009.

[60] G.Y. Yun, Influences of perceived control on thermal comfort and energy use in buildings, Energy and Buildings. 158 (2018) 822-830. doi:10.1016/j.enbuild.2017.10.044.

[61] M. Frontczak, P. Wargocki, Literature survey on how different factors influence human comfort in indoor environments, Building and Environment. 46 (2011) 922-937. doi:10.1016/j.buildenv.2010.10.021.

[62] J.K. Day, D.E. Gunderson, Understanding high performance buildings: The link between occupant knowledge of passive design systems, corresponding behaviors, occupant comfort and environmental satisfaction, Building and Environment. 84 (2015) 114-124. doi:10.1016/j.buildenv.2014.11.003. 
[63] M. Kwon, H. Remøy, A. van den Dobbelsteen, U. Knaack, Personal control and environmental user satisfaction in office buildings: Results of case studies in the Netherlands, Building and Environment. 149 (2019) 428-435. doi:10.1016/j.buildenv.2018.12.021.

[64] J. Langevin, P.L. Gurian, J. Wen, Tracking the human-building interaction: A longitudinal field study of occupant behavior in air-conditioned offices, Journal of Environmental Psychology. 42 (2015) 94-115. doi:10.1016/j.jenvp.2015.01.007.

[65] J. Kim, R. de Dear, T. Parkinson, C. Candido, Understanding patterns of adaptive comfort behaviour in the Sydney mixedmode residential context, Energy and Buildings. 141 (2017) 274-283. doi:10.1016/j.enbuild.2017.02.061.

[66] World Weather Information Service, Concepción weather 30-year period, Dirección Metereológica de Chile. (2019). https://worldweather.wmo.int/en/city.html?cityId=2202 (accessed June 27, 2019).

[67] R.K. Andersen, Occupant behaviour with regard to control of the indoor environment, Technical University of Denmark, 2009.

[68] S. Herkel, U. Knapp, J. Pfafferott, Towards a model of user behaviour regarding the manual control of windows in office buildings, Building and Environment. 43 (2008) 588-600. doi:10.1016/j.buildenv.2006.06.031.

[69] A. Field, Discovering Statistics Using IBM SPSS Statistics, 5th ed., SAGE, 2018.

[70] S. Sun, W. Pan, L.L. Wang, A Comprehensive Review of Effect Size Reporting and Interpreting Practices in Academic Journals in Education and Psychology, Journal of Educational Psychology. 102 (2010) 989-1004. doi:10.1037/a0019507.

[71] D. Sharpe, Your Chi-Square Test Is Statistically Significant: Now What? - Practical Assessment, Research \&amp; Evaluation, 20 (2013) 1-10.

[72] P.F. Pereira, N.M.M. Ramos, Occupant behaviour motivations in the residential context - An investigation of variation patterns and seasonality effect, Building and Environment. 148 (2018) 535-546. doi:10.1016/j.buildenv.2018.10.053.

[73] C.J. Ferguson, An Effect Size Primer: A Guide for Clinicians and Researchers, Professional Psychology: Research and Practice. 40 (2009) 532-538. doi:10.1037/a0015808.

[74] S. Altomonte, S. Schiavon, M.G. Kent, G.S. Brager, Indoor environmental quality and occupant satisfaction in green-certified buildings, Building Research \& Information. 47 (2019) 255-274. doi:10.1080/09613218.2018.1383715.

[75] F.J. Gravetter, L.B. Wallnau, Statistics for the Behavioral Sciences, 9th ed., Cengage Learning, Belmont, CA, United States, 2012.

[76] J. Kim, S. Schiavon, G.S. Brager, Personal comfort models - A new paradigm in thermal comfort for occupant-centric environmental control, Building and Environment. 132 (2018) 114-124. doi:10.1016/j.buildenv.2018.01.023.

[77] S. Shahzad, J. Brennan, D. Theodossopoulos, B.R. Hughes, J.K. Calautit, Energy and comfort in contemporary open plan and traditional personal offices, Applied Energy. 185 (2017) 1542-1555. doi:10.1016/j.apenergy.2016.02.100.

[78] V. Inkarojrit, Monitoring and modelling of manually-controlled venetian blinds in private offices: A pilot study, Journal of Building Performance Simulation. 1 (2008) 75-89. doi:10.1080/19401490802021012.

[79] S. Altomonte, P. Rutherford, R. Wilson, Human factors in the design of sustainable built environments, Intelligent Buildings International. 7 (2015) 224-241. doi:10.1080/17508975.2014.970121.

[80] R.V. Andersen, B.W. Olesen, J. Toftum, Modelling window opening behaviour in Danish dwellings, in: Indoor Air, 2011.

[81] K. Schakib-Ekbatan, F.Z. Çakici, M. Schweiker, A. Wagner, Does the occupant behavior match the energy concept of the building? - Analysis of a German naturally ventilated office building, Building and Environment. 84 (2015) 142-150. doi:10.1016/j.buildenv.2014.10.018.

[82] Y. Zhang, P. Barrett, Factors influencing occupants' blind-control behaviour in a naturally ventilated office building, Building and Environment. 54 (2012) 137-147. doi:10.1016/j.buildenv.2012.02.016.

[83] I. Bennet, W. O'Brien, H.B. Gunay, Effect of Window Blind Use in Residential Buildings: Observation and Simulation Study, in: ESIM 2014, Ottawa, Canada, 2014.

[84] A. Mahdavi, A. Mohammadi, E. Kabir, L. Lambeva, Occupants' operation of lighting and shading systems in office buildings, Journal of Building Performance Simulation. 1 (2008) 57-65. doi:10.1080/19401490801906502.

[85] V. Fabi, R.V. Andersen, S.P. Corgnati, Influence of occupant's heating set-point preferences on indoor environmental quality and heating demand in residential buildings, HVAC\&R Research. 19 (2013) 635-645. doi:10.1080/10789669.2013.789372.

[86] J.K. Day, Survey and Interview Approaches to Studying Occupants, in: A. Wagner, W. O’Brien, B. Dong (Eds.), Exploring Occupant Behavior in Buildings: Methods and Challenges, 1st ed., Springer, 2018: pp. 1-310. doi:10.1007/978-3-319-61464-9.

[87] J. Langevin, J. Wen, P.L. Gurian, Quantifying the human-building interaction: Considering the active, adaptive occupant in building performance simulation, Energy and Buildings. 117 (2016) 372-386. doi:10.1016/j.enbuild.2015.09.026. 
817

[88] M. Schweiker, Understanding Occupants' Behaviour for Energy Efficiency in Buildings, Current Sustainable/Renewable Energy Reports. 4 (2017) 8-14. doi:10.1007/s40518-017-0065-5.

[89] F. Haldi, D. Calì, R.K. Andersen, M. Wesseling, D. Müller, Modelling diversity in building occupant behaviour: a novel statistical approach, Journal of Building Performance Simulation. 1493 (2016) 1-18. doi:10.1080/19401493.2016.1269245.

[90] B. Kingma, G.M. Huebner, H. Pallubinsky, R. Kramer, M. Schweiker, Drivers of diversity in human thermal perception - A review for holistic comfort models, Temperature. 5 (2018) 308-342. doi:10.1080/23328940.2018.1534490.

[91] P.M. Bluyssen, Towards an integrated analysis of the indoor environmental factors and its effects on occupants, Intelligent Buildings International. 0 (2019) 1-9. doi:10.1080/17508975.2019.1599318.

[92] S.S. Korsavi, A. Montazami, J. Brusey, Developing a design framework to facilitate adaptive behaviours, Energy and Buildings. 179 (2018) 360-373. doi:10.1016/j.enbuild.2018.09.011.

[93] A. Paone, J.P. Bacher, The impact of building occupant behavior on energy efficiency and methods to influence it: A review of the state of the art, Energies. 11 (2018). doi:10.3390/en11040953.

[94] Y. Zhang, X. Bai, F.P. Mills, J.C.V. Pezzey, Rethinking the role of occupant behavior in building energy performance: A review, Energy and Buildings. 172 (2018) 279-294. doi:10.1016/j.enbuild.2018.05.017. 